\title{
Neuromedin B Expression Defines the Mouse Retrotrapezoid Nucleus
}

\author{
Yingtang Shi, ${ }^{1 \star}$ (Duth L. Stornetta, ${ }^{1 \star}$ Daniel S. Stornetta, ${ }^{1}$ Suna Onengut-Gumuscu, ${ }^{2,3}$ Emily A. Farber, ${ }^{2}$ \\ ¿Stephen D. Turner, ${ }^{3,4}{ }^{\circledR}$ Patrice G. Guyenet, ${ }^{1 \star}$ and ${ }^{\circledR D}$ Douglas A. Bayliss ${ }^{1 \star}$ \\ ${ }^{1}$ Department of Pharmacology, ${ }^{2}$ Center for Public Health Genomics, ${ }^{3}$ Department of Public Health Sciences, and ${ }^{4}$ School of Medicine Bioinformatics Core, \\ University of Virginia, Charlottesville, Virginia 22908
}

The retrotrapezoid nucleus (RTN) consists, by definition, of Phox2b-expressing, glutamatergic, non-catecholaminergic, noncholinergic neurons located in the parafacial region of the medulla oblongata. An unknown proportion of RTN neurons are central respiratory chemoreceptors and there is mounting evidence for biochemical diversity among these cells. Here, we used multiplexed in situ hybridization and single-cell RNA-Seq in male and female mice to provide a more comprehensive view of the phenotypic diversity of RTN neurons. We now demonstrate that the RTN of mice can be identified with a single and specific marker, Neuromedin B mRNA (Nmb). Most $(\sim 75 \%)$ RTN neurons express low-to-moderate levels of $N m b$ and display chemoreceptor properties. Namely they are activated by hypercapnia, but not by hypoxia, and express proton sensors, TASK-2 and Gpr4. These Nmb-low RTN neurons also express varying levels of transcripts for Gal, Penk, and Adcyap1, and receptors for substance P, orexin, serotonin, and ATP. A subset of RTN neurons ( 20$25 \%$ ), typically larger than average, express very high levels of $\mathrm{Nmb}$ mRNA. These $\mathrm{Nmb}$-high RTN neurons do not express Fos after hypercapnia and have low-to-undetectable levels of Kcnk5 or Gpr4 transcripts; they also express Adcyap1, but are essentially devoid of Penk and Gal transcripts. In male rats, $\mathrm{Nmb}$ is also a marker of the RTN but, unlike in mice, this gene is expressed by other types of nearby neurons located within the ventromedial medulla. In sum, $N m b$ is a selective marker of the RTN in rodents; Nmb-low neurons, the vast majority, are central respiratory chemoreceptors, whereas $\mathrm{Nmb}$-high neurons likely have other functions.

Key words: central chemoreceptors; Gpr4; hypercapnia; medulla oblongata; Neuromedin B; TASK-2

\section{Significance Statement}

Central respiratory chemoreceptors regulate arterial $\mathrm{PCO}_{2}$ by adjusting lung ventilation. Such cells have recently been identified within the retrotrapezoid nucleus (RTN), a brainstem nucleus defined by genetic lineage and a cumbersome combination of markers. Using single-cell RNA-Seq and multiplexed in situ hybridization, we show here that a single marker, Neuromedin B mRNA $(\mathrm{Nmb})$, identifies RTN neurons in rodents. We also suggest that $>75 \%$ of these $N m b$ neurons are chemoreceptors because they are strongly activated by hypercapnia and express high levels of proton sensors (Kcnk5 and Gpr4). The other RTN neurons express very high levels of $\mathrm{Nmb}$, but low levels of Kcnk5/Gpr4/pre-pro-galanin/pre-pro-enkephalin, and do not respond to hypercapnia. Their function is unknown.

\section{Introduction}

The term retrotrapezoid nucleus (RTN) was coined in 1989 to describe a region of the reticular formation that lies beneath the

Received July 19, 2017; revised Oct. 9, 2017; accepted Oct. 17, 2017.

Author contributions: Y.S., R.L.S., P.G.G., and D.A.B. designed research; Y.S., R.L.S., D.S.S., S.O.-G., E.A.F., and S.D.T. performed research;Y.S., R.L.S., S.O.-G., E.A.F., S.D.T.,P.G.G., and D.A.B. analyzed data;Y.S., R.L.S., P.G.G., and D.A.B. wrote the paper.

This work was supported by HL074011 (P.G.G.), and HL108609 and Pilot Grant Award from the CCHS Family Network (D.A.B.). We thank Drs. Mike McConnell and lan Burbulis for early advice and support on single-cell sequencing approaches.

The authors declare no competing financial interests.

*Y.S. and R.L.S. are co-first authors. P.G.G. and D.A.B. are co-senior authors.

Correspondence should be addressed to Dr. Ruth Stornetta, University of Virginia Health System, Pinn Hall, Room 5228, 1340 Jefferson Park Avenue, P.0. Box 800735, Charlottesville, VA 22908-0735. E-mail: rs3j@virginia.edu. facial motor nucleus and provides input to the ventrolateral and dorsomedial medulla oblongata (Smith et al., 1989; Connelly et al., 1990; Ellenberger and Feldman, 1990). This brain area, also called the parafacial region (Onimaru and Homma, 2003; Huckstepp et al., 2015), has long been suspected to contain central respiratory chemoreceptors (Loeschcke, 1982; Liu et al., 2002; Feldman et al., 2003). Since 2004, a substantial set of evidence has accrued to indicate that the parafacial region harbors the hub of the central respiratory chemoreflex, and may be the principal CNS site where $\mathrm{CO}_{2}$ is sensed for the purpose of breathing regu-

DOI:10.1523/JNEUROSCI.2055-17.2017

Copyright $\odot 2017$ the authors $\quad 0270-6474 / 17 / 3711744-14 \$ 15.00 / 0$ 
lation (for reviews, see Guyenet and Bayliss, 2015; Guyenet et al., 2016). Identifying the phenotype of these chemoreceptors has been an iterative process, guided by the gradual and often fortuitous discovery of biochemical markers expressed by the parafacial neurons that are activated by acidification in slices or by hypercapnia in vivo (Mulkey et al., 2004; Stornetta et al., 2006). It is now clear that these parafacial acid-sensitive neurons express Phox 2b, vesicular glutamate transporter-2 (VGlut2), and NK1 receptors from late embryological stages to adulthood; by contrast, they lack tyrosine hydroxylase, choline acetyltransferase, glutamic acid decarboxylases, glycine transporter-2, and tryptophan hydroxylase (Mulkey et al., 2004; Dubreuil et al., 2008; Lazarenko et al., 2009; Thoby-Brisson et al., 2009; Wang et al., 2013b; Onimaru et al., 2014; Kumar et al., 2015; Guyenet et al., 2016). This combination of markers defines a population of $600-$ 800 parafacial neurons in mice ( $\sim 2000$ in rats) that also have a common developmental lineage (Egr-2, Phox $2 \mathrm{~b}$, Atoh-1), and which are now referred to specifically as the RTN (Ramanantsoa et al., 2011; Ruffault et al., 2015; Guyenet et al., 2016). RTN neurons innervate the ventrolateral and dorsomedial medulla oblongata, as per the original definition of the term (Smith et al., 1989; Connelly et al., 1990; Ellenberger and Feldman, 1990). They drive breathing in proportion to arterial $\mathrm{pH}$ as expected from central respiratory chemoreceptors (Basting et al., 2015). It is now well established that the parafacial $\mathrm{CO}_{2}$-responsive neurons have the combined neurochemical phenotype expected of RTN neurons; conversely, whether every RTN neuron is a respiratory chemoreceptor remains an open question.

Recent evidence suggests that two proton-sensitive membrane proteins - $\mathrm{a} \mathrm{H}^{+}$-inhibited background $\mathrm{K}^{+}$channel, TASK-2 (encoded by Kcnk5), and a $\mathrm{H}^{+}$-activated G-protein-coupled receptor, Gpr4 - underlie the intrinsic pH-sensitivity of RTN neurons in vitro and contribute to their central respiratory chemoreceptor properties in vivo (Reyes et al., 1998; Ludwig et al., 2003; Gestreau et al., 2010; Wang et al., 2013b; Kumar et al., 2015). Thus, these proteins could be selective markers of the RTN neurons that have chemoreceptor properties.

RTN neurons are biochemically heterogeneous. Subsets of RTN neurons, including the putative chemoreceptors, express the neuropeptide galanin (Stornetta et al., 2009). The parafacial region also contains Neuromedin $\mathrm{B}(\mathrm{Nmb})$-expressing neurons (Lein et al., 2007) that may control sighing (Li et al., 2016). Given their location, these $N m b$ neurons could be a subtype of RTN neurons.

Here, we used multiplexed in situ hybridization and single-cell RNA-Seq to provide a more comprehensive view of the phenotypic diversity of RTN neurons. Our primary objectives were to address the following questions. Are the recently identified parafacial $N m b$ neurons a subset of the neuronal population that we previously defined as RTN? Is there a unique marker of RTN neurons that could simplify their identification? Does the entire population of RTN neurons qualify as central respiratory chemoreceptors? If not, does the presence of the putative proton receptors Gpr4 and or TASK-2 predict their $\mathrm{CO}_{2}$ sensitivity?

\section{Materials and Methods}

Animals

JX99 (Phox2b::eGFP BAC transgenic) mice were originally obtained from the Gene Expression Nervous System Atlas Project at Rockefeller University and have been maintained on a mixed genetic background (Lazarenko et al., 2009). C57BL/6J mice were obtained from Jackson Laboratories (RRID:IMSR_JAX:000664). Three male Sprague-Dawley rats were obtained from Taconic (RRID:RGD_1566440). Under the su-
Table 1. Probes used for in situ hybridization

\begin{tabular}{llll}
\hline Probe & ACD Catalog\# & $\begin{array}{l}\text { No. of } \\
\text { pairs }\end{array}$ & $\begin{array}{l}\text { Targeted region (sequence } \\
\text { accession no.) }\end{array}$ \\
\hline Neuromedin-B (mouse) & $459931(C 1) ; 459931-C 3$ & 14 & bp 14-685 (NM_001291280.1) \\
Neuromedin-B (rat) & $494791(C 1)$ & 13 & bp 2-651 (NM_001109149.1) \\
Tyrosine Hydroxylase & $317621(C 1) ; 317621-C 3$ & 20 & bp 483-1603 (NM_009377.1) \\
Galanin & $400961-C 3$ & 12 & bp 43-652 (NM_010253.3) \\
Pre-pro-Enkephalin & $318761-C 2$ & 20 & bp 106-1332 (NM_001002927.2) \\
TASK-2 (Kcnk5) & $527951-C 3$ & 20 & bp 659-1827 (NM_021542.4) \\
Gpr4 & $427941(C 1)$ & 20 & bp 866-1900 (NM_175668.4) \\
VGlut2 (SIc17a6) & 319171 (C1);319171-C3 20 & bp 1986-2998 (NM_080853.3) \\
GAD1 & 400951 (C1) & 15 & bp 62-3113 (NM_008077.4) \\
PACAP (Adcyap1) & $405911-C 2$ & 20 & bp 702-1839 (NM_009625.2) \\
Fos (FBJ osteosarcoma & $316921-C 3$ & 20 & bp 407-1427 (NM_010234.2) \\
$\quad$ & & & \\
oncogene) & $407861-C 2$ & 20 & bp 1642-2764 (NM_0088888.3) \\
Phox2b & & 17 & bp 2-849 (NM_008890.1) \\
Phenylethanolamine-N- & $426421(C 1)$ & & \\
$\quad$ methyltransferase & & & \\
$\quad$ (PNMT) & & & \\
\hline
\end{tabular}

pervision of the University of Virginia veterinary staff, all animals were kept in the Pinn Hall vivarium and allowed ad libitum access to food and water with a $12 \mathrm{~h}$ day/night light cycle. All protocols were approved by the University of Virginia Animal Care and Use Committee and complied with NIH animal guidelines.

\section{Immunocytochemistry}

Antibodies. Phox $2 \mathrm{~b}:: \mathrm{eGFP} J X 99$ mice express eGFP in all Phox $2 \mathrm{~b}$ neurons (Lazarenko et al., 2009). To enhance sensitivity, eGFP was visualized with a chicken antibody to GFP from Aves Labs (catalog \#GFP-1020; concentration 1:1000; RRID:AB_10000240) followed by a secondary antichicken antibody tagged with Alexa488 (Jackson ImmunoResearch; RRID:SCR_010488).

In situ hybridization. Mice ( $N=37 ; 20$ females, 17 males) were anesthetized with pentobarbital and perfused transcardially with $4 \%$ paraformaldehyde. Brains were removed and postfixed in the same fixative for $16-18 \mathrm{~h}$ at $4^{\circ} \mathrm{C}$. Brains were sectioned and placed in cryoprotectant (30\% ethylene glycol, 20\% glycerol, 50 mM sodium phosphate buffer, $\mathrm{pH} 7.4$ ) at $-20^{\circ} \mathrm{C}$ until further processing. Sections were briefly washed in sterile PBS, mounted on charged slides, and dried overnight. All sections for an experimental "run" were mounted and reacted on the same slide and thus experienced the same experimental conditions and solutions. After two rinses in sterile water, sections were incubated with "pretreat 4" from the RNAscope Multiplex Fluorescent Assay kit [Advanced Cell Diagnostics (ACD); RRID:SCR_012481] for $30 \mathrm{~min}$ at $40^{\circ} \mathrm{C}$. Sections were rinsed twice in sterile water and incubated in RNAscope catalog oligonucleotide probes for Nmb, tyrosine hydroxylase (Th), pre-pro-Galanin (Gal), Pre-proenkephalin (Penk), Kcnk5, Gpr4, VGlut2 (Slc17a6), Fos, glutamate decarboxylase 1 (Gad1), Pituitary adenylate cyclase-activating polypeptide (PACAP; Adcyap1), or phenylethanolamine- $N$-methyltransferase (Pnmt) transcripts as listed in Table 1 for $2 \mathrm{~h}$ at $40^{\circ} \mathrm{C}$. After incubation with probes, tissue was treated according to the manufacturer's protocol (ACD). When eGFP enhancement was required, sections were first subjected to the in situ hybridization (ISH) protocol and then rinsed $2 \times 2 \mathrm{~min}$ in blocking buffer $(10 \%$ horse serum, $0.1 \%$ Triton in $100 \mathrm{~mm}$ Tris buffer), incubated for $1 \mathrm{~h}$ in chicken GFP antibody (1:1000) in blocking buffer. Sections were rinsed $2 \times 2 \mathrm{~min}$ in Tris buffer, incubated for $30 \mathrm{~min}$ in antichicken IgG tagged with AlexaFluor 488 (1:500) in Tris buffer, then rinsed and allowed to air dry. Slides were covered with Prolong Gold with DAPI Anti-fade mounting medium (Invitrogen). 
Effect of hypercapnia or hypoxia on Fos expression by RTN neurons

Mice were placed in chambers designed for whole-body plethysmography (Data Sciences International; Kumar et al., 2015). Mass flow regulators provided quiet, constant, and smooth flow through the chamber $(0.5 \mathrm{~L} / \mathrm{min})$ and delivered $21 \% \mathrm{O}_{2}$ (balance $\mathrm{N}_{2}$ ) during the habituation period $(1 \mathrm{~h})$. Mice were then exposed for $35 \mathrm{~min}$ to either normoxia $\left(21 \% \mathrm{O}_{2}\right.$; $n=11)$, hypercapnia $\left(15 \% \mathrm{FiCO}_{2} / 21 \% \mathrm{FiO}_{2} /\right.$ balance $\left.\mathrm{N}_{2} ; n=7\right)$, or hypoxia $\left(8 \% \mathrm{O}_{2} /\right.$ balance $\left.\mathrm{N}_{2} ; n=5\right)$. Preliminary experiments showed that $8 \% \mathrm{O}_{2}$ induced a large $(\sim 4$-fold) increase in sigh frequency, whereas less severe hypoxia $\left(10 \% \mathrm{FiO}_{2}\right)$ had very little effect $(<50 \%$ increase). Hypercapnic exposure was under normoxic conditions because preliminary experiments revealed that hyperoxia $(30 \mathrm{~min}$; $65 \% \mathrm{FiO}_{2}$, no $\mathrm{CO}_{2}$ added; 2 mice), unlike normoxia, caused Fos expression in $10-15 \%$ of RTN neurons. In humans, sustained hyperoxia produces a mild hyperventilation and arterial hypocapnia consistent with the possibility that central respiratory chemoreceptors might be activated (Becker et al., 1996). Our evidence suggests that this might be the case in mice as well. After exposure to $35 \mathrm{~min}$ of hypercapnia, hypoxia, or normoxia, mice were immediately anesthetized and perfused transcardially with fixative as described above. All experiments, including the histology, were run in pairs (a normoxia control and a mouse exposed to hypercapnia or hypoxia). All plethysmography experiments were conducted between 12:00 and 5:00 P.M.

\section{Neuron mapping and counting}

A one-in-three or one-in-six series of $30 \mu \mathrm{m}$ transverse sections through the brain was examined for each experiment under bright-field and epifluorescence using a Zeiss AxioImager Z.1 or a Zeiss AxioImager M2 microscope (Carl Zeiss Microimaging). Neurons were plotted with the Neurolucida software (Micro Brightfield; RRID:SCR_001775) using a Ludl motor driven microscope stage and a Zeiss MRC or Hamamatsu C11440 Orca-Flash 4.0LT digital camera, after methods previously described (Stornetta et al., 2004). Filter settings for AlexaFluor 488, Atto 550, and Atto 647 fluorophores were as follows: AlexaFluor 488, excitation of $500 \mathrm{~nm}$, emission of $535 \mathrm{~nm}$; Atto 550, excitation of 545, emission of $605 \mathrm{~nm}$; Atto 647 , excitation of $640 \mathrm{~nm}$, emission of $690 \mathrm{~nm}$. Only cell profiles that included a nucleus were counted and/or mapped. Sections were matched as closely as possible to brain levels with reference to bregma using the atlas of Paxinos and Franklin (2013). Cells were counted and mapped bilaterally. Most mapping was limited to the ventral half of the brainstem which contains the distinctive and isolated parafacial cluster of $\mathrm{Nmb}+$ neurons.

Photographs were taken with a Hamamatsu C11440 Orca-Flash 4.0LT digital camera (resolution $2048 \times 2048$ pixels) and the resulting TIFF files were first exported into Fiji (RRID:SCR_002285) and unsharp mask filter and/or brightness/contrast adjusted for clarity and to reflect true rendering as much as possible. Images were not otherwise altered. TIFF images were imported into Canvas v10 (ACD; RRID:SCR_014312) for labeling and final presentation. The neuroanatomical nomenclature is after Paxinos and Franklin (2013).
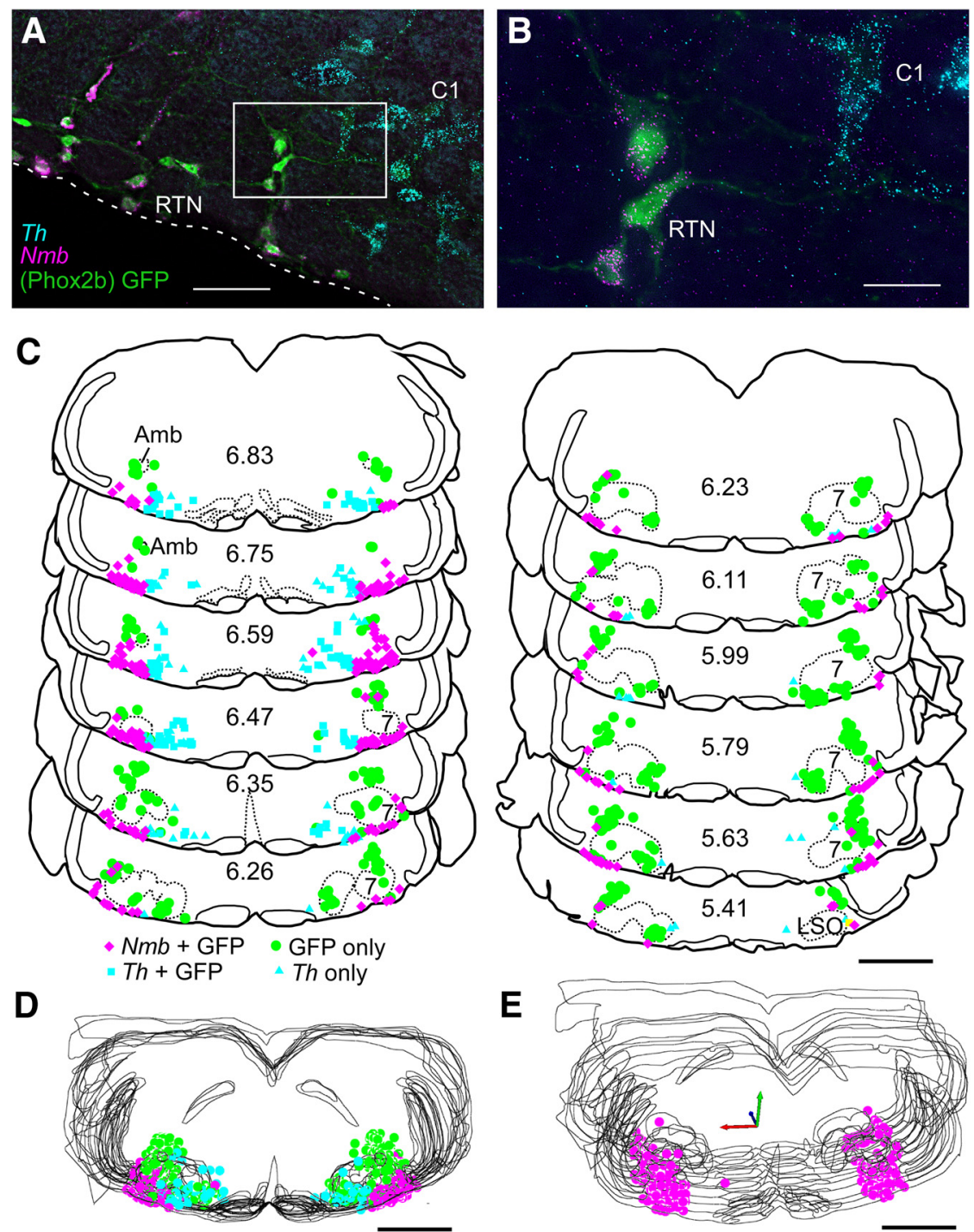

Figure 1. $\quad N m b$-positive parafacial neurons express Phox2b but are not catecholaminergic. $A$, Photomicrograph of a coronal section from a Phox2b::eGFP mouse with eGFP-labeled RTN neurons (green; Phox2b) containing Nmb transcripts (magenta); these neurons do not contain transcripts for $T h$, unlike the nearby $C 1$ adrenergic cells ( $T h$; blue). Medial to the right, dorsal toward the top. White dashed line represents the ventral medullary surface. $\boldsymbol{B}$, Enlargement of white boxed area in $\boldsymbol{A}$. $\boldsymbol{C}$, Computer stage-assisted drawings of coronal sections showing the distribution of Phox2b-only (green filled circles), Th-only (blue triangles), $T h+$ Phox $2 b$ (blue squares), and $\mathrm{Nmb}+$ Phox2b neurons (magenta diamonds) in ventral half of the brainstem through the rostral medulla and pons. Approximate millimeters behind bregma (after Paxinos and Franklin, 2013) indicated by numbers in lower center of each section. Abbreviations: 7, Facial motor nucleus; Amb, ambiguus nucleus; LSO, lateral superior olive. D, Sections from C collapsed in a stack to give a general representation of the location of $\mathrm{Nmb}$ neurons as ventrolateral to $T h$ as well as Phox $2 \mathrm{~b}$-only neurons in the through the RTN in medulla/pons. Note the bulk of the $\mathrm{Nmb}$ neurons are ventral and lateral to the facial motor nucleus. Scale bars: $\boldsymbol{A}, 60 \mu \mathrm{m} ; \boldsymbol{B}, 20 \mu \mathrm{m} ; \boldsymbol{C}-\boldsymbol{E}, 1 \mathrm{~mm}$

\section{Single-cell transcriptome of RTN neurons}

For single-cell collection, we adapted previously described procedures to harvest eGFP-labeled neurons from brainstem slices obtained from JX99 mice (Kumar et al., 2015; Shi et al., 2016), specifically targeting cells in the region ventrolateral to the facial nucleus to bias our sampling toward obtaining RTN neurons and avoiding other Phox 2b-expressing cell types (e.g., C1 neurons, facial motor neurons). Briefly, mice ( $n=22$ with both sexes represented, P11-P120) were anesthetized with ketamine and $\mathrm{xy}$ lazine $(375 \mathrm{mg} / \mathrm{kg}$ and $25 \mathrm{mg} / \mathrm{kg}$, i.m.) and rapidly decapitated; brainstems were immediately removed and slices $(300 \mu \mathrm{m})$ cut with microslicer (DTK Zero 1; Ted Pella) in an ice-cold, sucrose-substituted Ringer's solution containing the following (in $\mathrm{mm}$ ): 260 sucrose, $3 \mathrm{KCl}$, $5 \mathrm{MgCl}_{2}, 1 \mathrm{CaCl}_{2}, 1.25 \mathrm{NaH}_{2} \mathrm{PO}_{4}, 26 \mathrm{NaHCO}_{3}, 10$ glucose, and 1 kynurenic acid. 
Table 2. Counts of all cells containing Nmb transcripts in the parafacial area for 37 mice

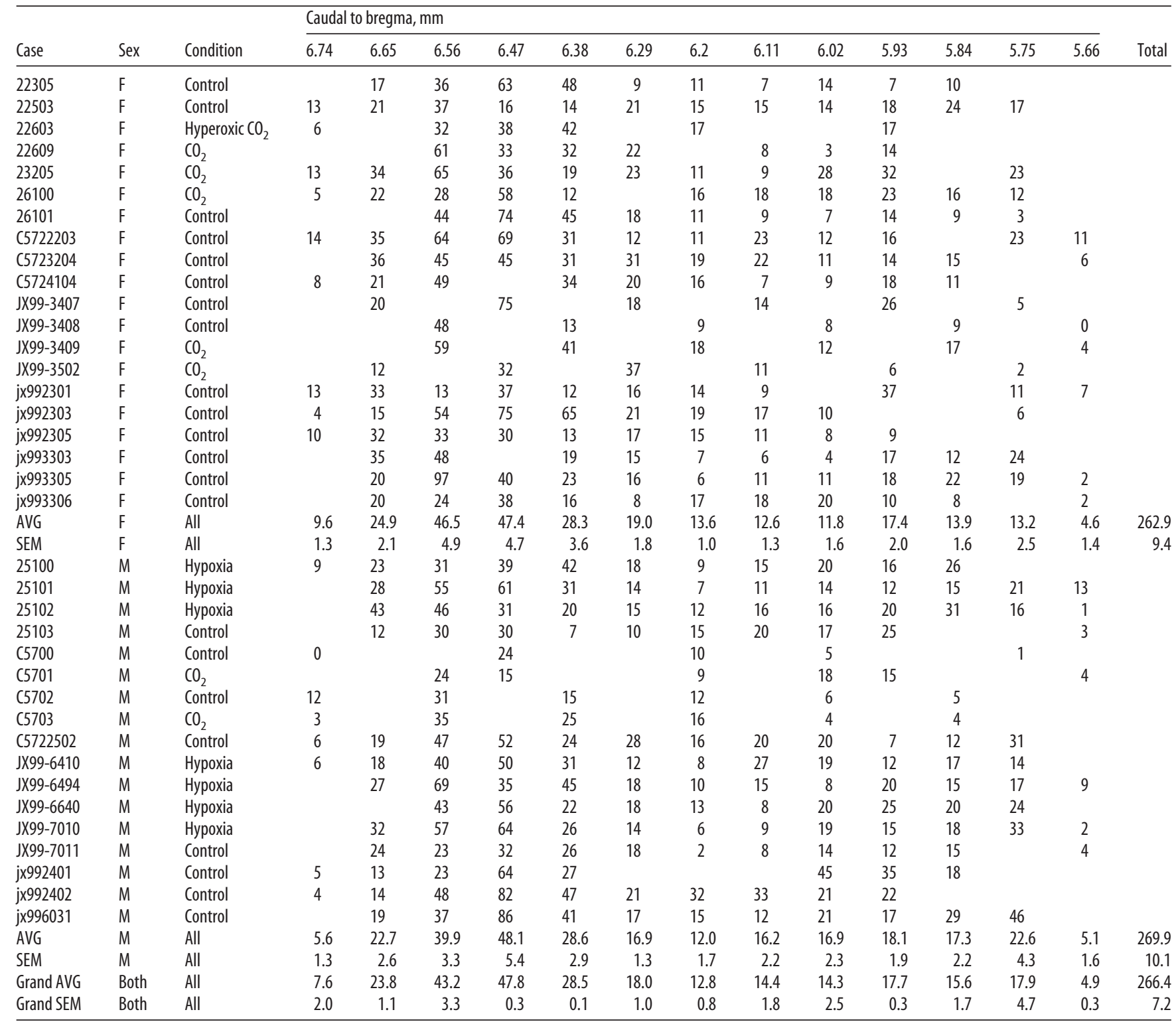

AVG, Average; $\mathrm{CO}_{2}, 15 \% \mathrm{CO}_{2} ; \mathrm{F}$, female; $\mathrm{M}$, male; hypoxia, $8 \% \mathrm{O}_{2}$.

Slices were incubated for $30 \mathrm{~min}$ at $37^{\circ} \mathrm{C}$, and subsequently at room temperature, in normal Ringer's solution containing the following (in m) : $130 \mathrm{NaCl}, 3 \mathrm{KCl}, 2 \mathrm{MgCl}_{2}, 2 \mathrm{CaCl}_{2}, 1.25 \mathrm{NaH}_{2} \mathrm{PO}_{4}, 26 \mathrm{NaHCO}_{3}$, and 10 glucose. The cutting and incubation solutions were bubbled with $95 \% \mathrm{O}_{2}$ and $5 \% \mathrm{CO}_{2}$. Slices were prepared in the early-to-late morning, and used for harvesting neurons from the late morning through the afternoon.

Single RTN neurons were collected for molecular analysis in a recording chamber mounted on a fluorescence microscope (Zeiss Axio Imager FS) in HEPES-based perfusate, containing the following (in mM): 140 $\mathrm{NaCl}, 3 \mathrm{KCl}, 2 \mathrm{MgCl}_{2}, 2 \mathrm{CaCl}_{2}, 10$ HEPES, 10 glucose. Under direct vision $(60 \times$ objective), viable cells were identified and the entire cell was aspirated into pre-baked pipettes $\left(24 \mathrm{~h}, 200^{\circ} \mathrm{C}\right)$ filled with sterile HEPESbased solution. The pipette was broken into a $0.2 \mathrm{ml}$ RNase-free PCR tube containing ice-cold cell lysis mix before performing RNA reverse transcription and cDNA amplification using the SMART-Seq v4 kit, according to the manufacturer's instructions (Clontech, catalog \#634896). Each amplification experiment included $10 \mathrm{pg}$ positive control RNA (from SMART-Seq kit) and a water-only negative control. cDNA concentration was quantified using Qubit dsDNA High-Sensitivity Assay Kit (ThermoFisher Scientific, catalog \#Q32854). To select single-cell cDNA

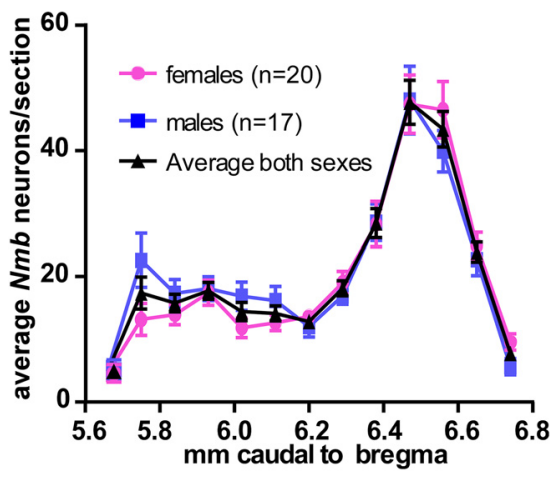

Figure 2. Distribution of parafacial $\mathrm{Nmb}$ neurons. Average total numbers of parafacial $\mathrm{Nmb}$ expressing neurons per $30-\mu \mathrm{m}$-thick transverse section (SEM indicated by vertical bars). Abscissa indicates the location of the sampled tissue sections (distance from bregma after Paxinos and Franklin, 2013). 
samples suitable for library construction, we predetermined expression of Gapdh, VGlut2, Phox $2 b, T h$, and Gad 1 in each sample by nested PCR; samples positive for Th and/or Gad 1 were deemed to be contaminated with other, nonRTN neurons. We used 0.5-1 ng of the amplified cDNA and the Nextera XT DNA Library kit (Illumina, catalog \#FC-131-1096; RRID: SCR_010233) to prepare dual-indexed libraries that were assessed for concentration and library quality using Qubit and the Agilent High Sensitivity D1000 TapeStation. These libraries (12-40 per batch) were pooled in a single lane on an Illumina NextSeq500, and sequenced to generate $75 \mathrm{bp}$ paired-end reads. FASTQ files from five sequencing runs were quasi-mapped to the mouse reference transcriptome (Ensembl GRCm38) as described by Patro et al. (2017), with 3-14 million reads per library $(50-80 \%$ mapped). Transcript abundance was summarized to the gene level normalized as transcripts per million (TPM), according to Soneson et al. (2015). In two early sequencing runs, 12 cell samples were included per sequencing lane often yielding $>10 \times 10^{6}$ reads per cell; because rarefaction analysis of these runs indicated a negligible loss in gene representation when reads were reduced to $<1 \times 10^{6}$ reads per cell $(<5 \%)$, we assayed greater numbers of cells per lane (32-40) at lower sequencing depth $\left(3-5 \times 10^{6}\right.$ reads $)$ in three subsequent runs.

\section{Statistics}

Values are presented as means \pm SEM, or as medians with ranges, as appropriate. Either one-way or two-way ANOVA or $t$ tests (both parametric or nonparametric) were performed as appropriate after verification of normality assumptions for these tests. TPM data were not normally distributed, and were analyzed using a Kruskal-Wallis ANOVA. All statistical tests were done using PRISM v7 (GraphPad Software).
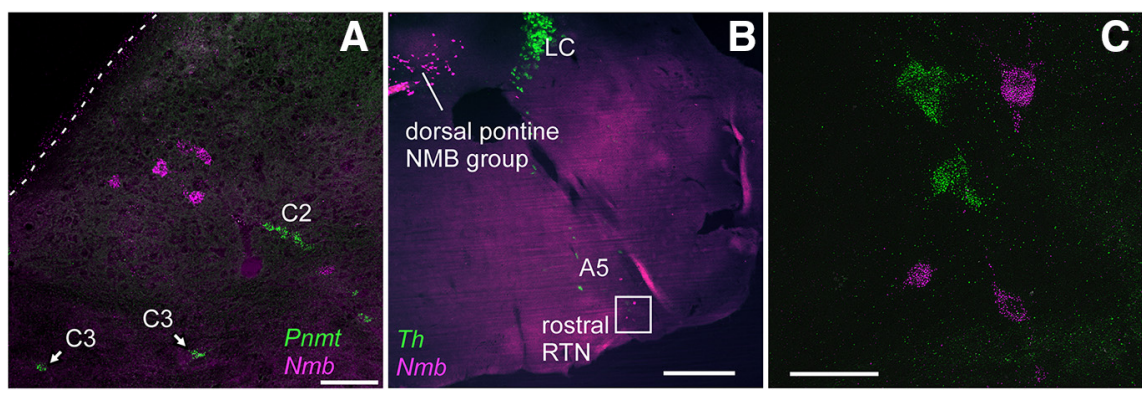

Figure 3. Nmb cells in rostral parafacial region and dorsal pons are not catecholaminergic. $A$, Transcripts for Pnmt (green) and $\mathrm{Nmb}$ (magenta) in dorsal medial medulla at level of $\mathrm{C} / \mathrm{C} 3$ adrenergic cell groups. $\boldsymbol{B}$, Transcripts for Th (green) and Nmb (magenta) in more rostral pontine brain regions. LC, locus coeruleus. $C$, Enlargement of the white box (rostral RTN) in $\boldsymbol{A}$. Scale bars: $\boldsymbol{A}, 100 \mu \mathrm{m} ; \boldsymbol{B}, 500$ $\mu \mathrm{m} ; C, 50 \mu \mathrm{m}$.

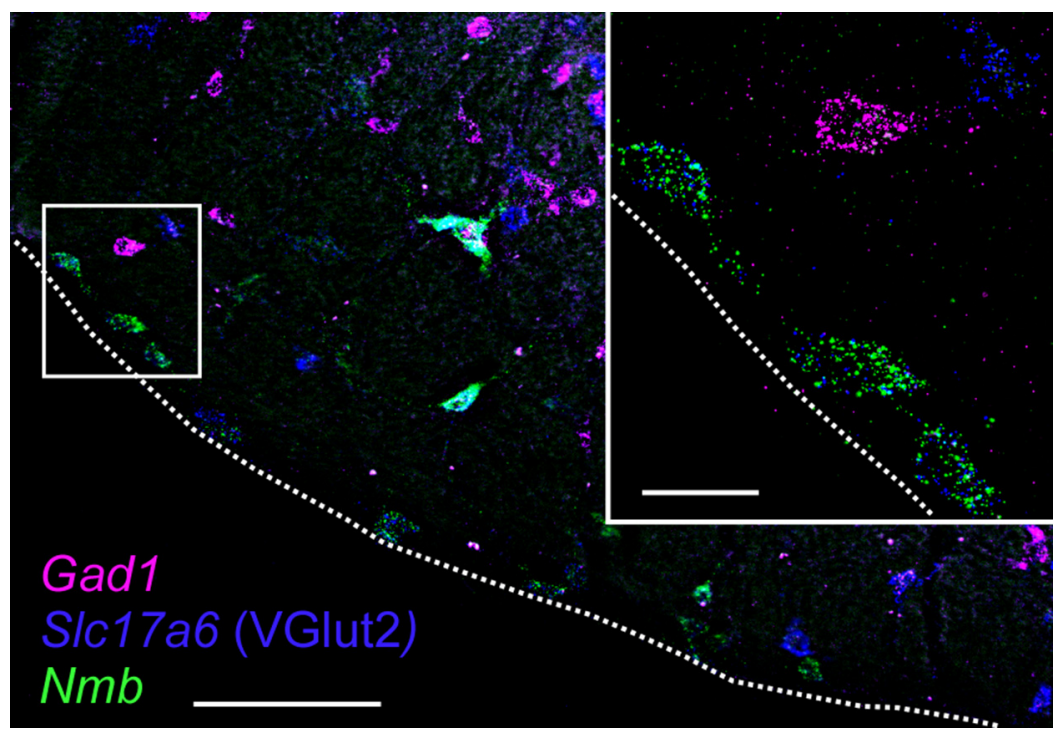

Figure 4. Parafacial Nmb neurons are glutamatergic but not GABAergic. Photomicrograph of coronal section of caudal RTN region with $\mathrm{Nmb}$ transcripts in green, VGlut2 transcripts in blue and Gad1 transcripts in magenta. Inset, Enlargement of boxed area with three RTN $\mathrm{Nmb}$ neurons along ventral surface that also express VGlut2 transcripts. Note that all neurons that contain Nmb transcripts, including the larger and more dorsal cells that express high levels of Nmb, also contain VGlut2 transcripts; none of the Nmb neurons contain Gad1 transcripts. Dashed white lines represent the ventral medullary surface. Scale bars: larger image, $100 \mu \mathrm{m}$; inset, $20 \mu \mathrm{m}$.

\section{Results}

\section{Distribution of $N m b$ transcripts in the rostral medulla and pons of mice}

By multiplex ISH, we observed a distinctive and isolated cluster of cells containing $\mathrm{Nmb}$ transcripts in the parafacial region of the rostral ventrolateral medulla oblongata and pons (Fig. 1A,E). Only two additional groups of $\mathrm{Nmb}$ cells (see below) were identified in the pons and rostral medulla oblongata. Both were located in the dorsal third of the brainstem and were clearly separated from the parafacial cluster.

The parafacial group of $\mathrm{Nmb}+$ cells was observed from $\sim 350$ $\mu \mathrm{m}$ caudal to the caudal pole of the facial motor nucleus, extending rostrally to the exit of the seventh nerve (Fig. 1C). Caudal to the facial motor nucleus, Nmb-expressing cells clustered predominantly along the ventral medullary surface but a few were scattered more dorsally within the ventrolateral medulla, approaching the level of nucleus ambiguus. At this caudal level, where $\mathrm{C} 1$ adrenergic neurons are also located, most $\mathrm{Nmb}$ cells were located ventrolateral to those $T h$ mRNA-expressing neurons, with minimal overlap between the two groups of cell soma (Fig. $1 A, C$ ). More rostrally, the bulk of the Nmb cells resided below the facial motor nucleus from its medial border to the medial edge of the trigeminal tract. At these rostral levels, $\mathrm{Nmb}$ cells tended to congregate close to the trigeminal tract, with a few of these neurons found around the lateral edge of, and dorsal to, the facial motor nucleus (Fig. 1C).

Using one-in-three or one-in-six series of $30 \mu \mathrm{m}$ sections from 37 mice (17 males, 20 females), cells containing Nmb transcripts were counted bilaterally within each section. Averages were taken across each bregma level and then added to determine a total average number of cells containing $N m b$ transcripts (Table 2). Using this method, we counted $266.4 \pm 7.2 \mathrm{Nmb}$ cells per mouse averaged across all mice (males: $269.9 \pm 10.0$; females: $262.9 \pm 9.4$; Fig. 2; Table 2). The number of Nmb cells and their distribution across the medulla/pons was not significantly different between sexes (Fig. 2; two-way ANOVA; main effect of sex: $F_{(1,328)}=0.21, p=0.65$; interaction between sex and bregma level: $\left.F_{(12,328)}=0.92, p=0.53\right)$. Combining data from both sexes, and after Abercrombie correction using an average nuclear width of $6.0 \pm 0.2 \mu \mathrm{m}$ measured from 50 cells in 3 mice (Abercrombie, 1946), we calculate an average total number of $\mathrm{Nmb}$ RTN cells in the mouse at 665 cells. 

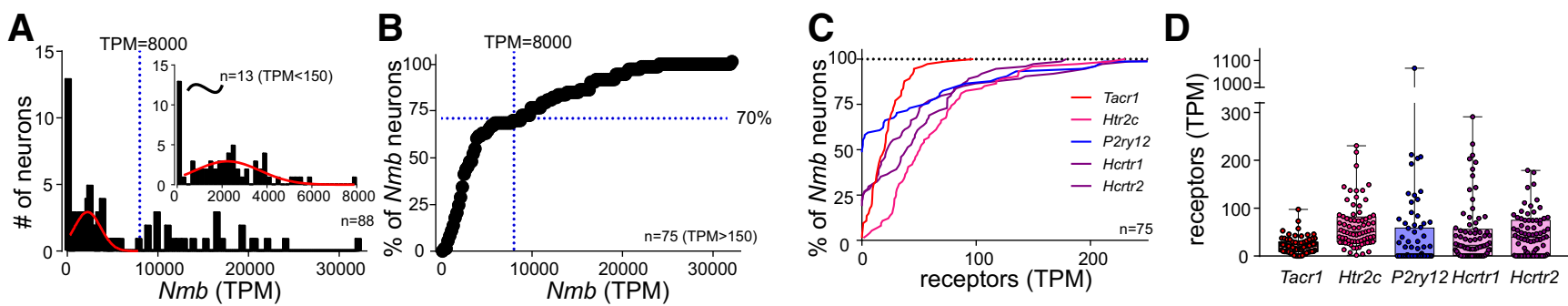

Figure 5. Two populations of parafacial $N m b$ neurons based on expression levels. $\boldsymbol{A}, \boldsymbol{B}$, Frequency $(\boldsymbol{A})$ and cumulative probability $(\boldsymbol{B})$ distributions for $N m b$ transcript levels assessed by RNA-Seq in individual GFP-expressing neurons from the RTN region ( $n=88$ ). A subset of neurons expressed extremely low levels of Nmb (TPM $<150, n=13$ ). Among the Nmb-expressing neurons ( $n=$ 75), a major subgroup of neurons contains moderate levels of $\mathrm{Nmb}$ transcripts ( 70\%; TPM $<8000$ ), whereas a smaller subgroup of cells express much higher levels of $\mathrm{Nmb}$ ( $\sim 30 \%$; TPM $>8000)$. C, Cumulative probability distributions of transcript levels for select G-protein-coupled receptors in Nmb-expressing neurons; the percentage of non-expressing neurons can be estimated from the $y$-intercept $($ TPM $=0)$. D. Expression levels for the indicated receptors in individual Nmb-expressing RTN neurons; in this and other plots of TPM data, the box-and-whiskers represent the median, 25th and 75th percentile, and the range.
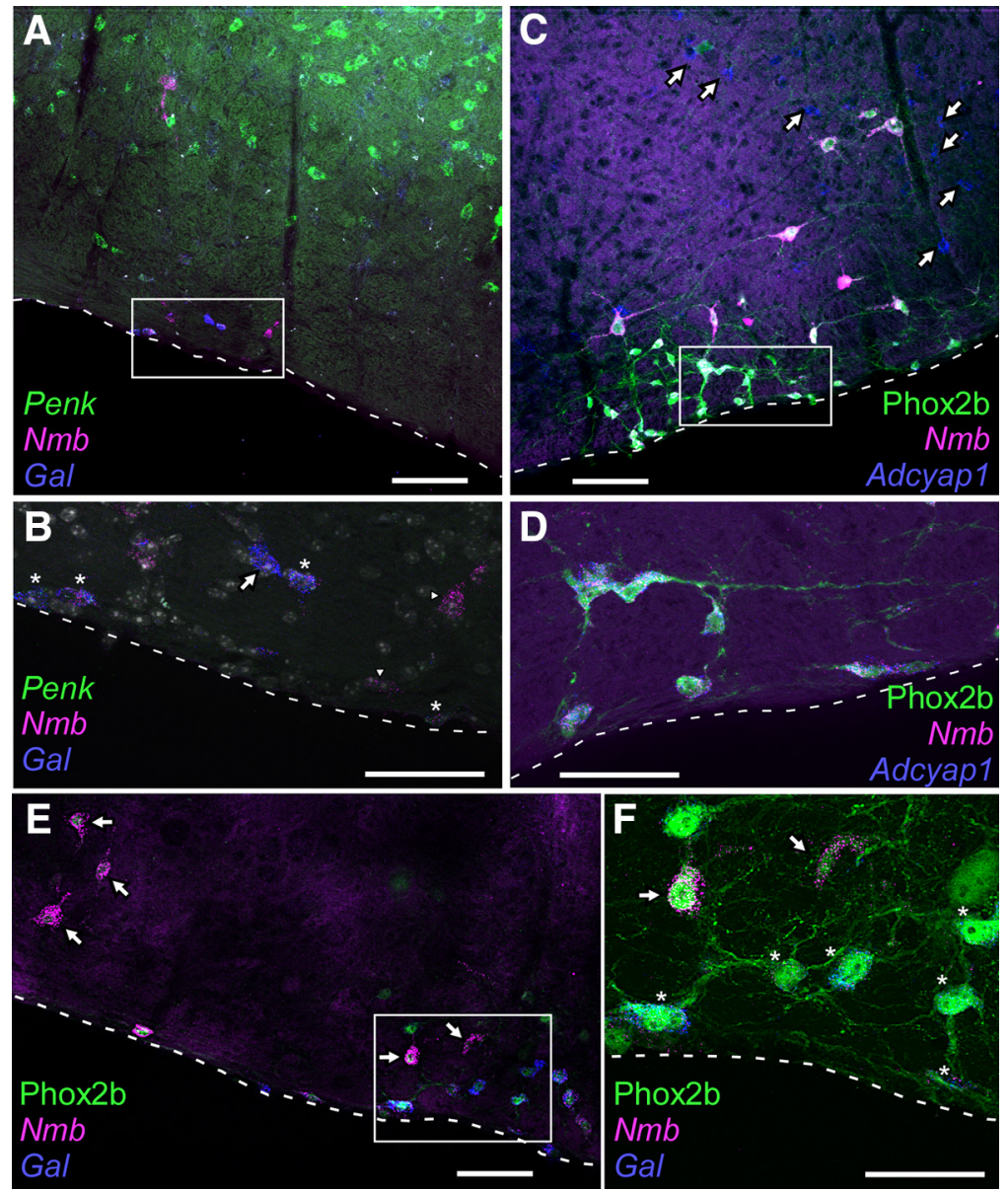

Figure 6. Parafacial Nmb neurons also contain other neuropeptides, including enkephalin, galanin and pituitary adenylate cyclase-activating peptide. A, Photomicrograph of coronal section showing transcripts for Nmb (magenta), Penk (green), and Gal (blue) in the caudal RTN region (level 6.7-6.8 from Fig. 1C). Note the widespread distribution of Penk within the reticular formation dorsal to RTN. Medial to the right, dorsal toward the top. $B$, Enlargement of the boxed inset from $A$ showing $N m b$ neurons with both Penk and Gal (stars), an Nmb neuron with Gal and not Penk (arrow) and neurons in which only Nmb was detectable (arrowheads). Nuclei stained with DAPI (white/gray). C, Photomicrograph showing transcripts for Nmb (magenta) and Adcyap 1 (blue) in eGFPimmunoreactive (i.e., Phox2b) neurons (green). Note that Adcyap1 transcripts are also expressed outside the RTN (arrows). D, Enlargement of boxed area in C. Note that all Nmb neurons express Adcyap1. Medial to the left, dorsal toward the top. $\boldsymbol{E}$, Photomicrograph of parafacial regions showing eGFP-immunoreactivity (i.e., Phox2b; green), Nmb transcripts (magenta) and Gal transcripts (blue) neurons. Every neuron is Phox2b. Large neurons with high levels of Nmb transcripts (arrows) do not contain $\mathrm{Gal}$. $\boldsymbol{F}$, Enlargement of boxed area in $\boldsymbol{E}$. Nmb-high neurons (arrows) without $\mathrm{Gal}$ are generally dorsal to the $\mathrm{Nmb}$-low neurons with $\mathrm{Gal}$ (stars). Dashed white lines on all panels represent the ventral medullary surface. Scale bars: $\boldsymbol{A}, 100 \mu \mathrm{m} ; \boldsymbol{B}, 50$ $\mu \mathrm{m} ; \boldsymbol{C}, 100 \mu \mathrm{m} ; \boldsymbol{D}, 50 \mu \mathrm{m} ; \boldsymbol{E}, 100 \mu \mathrm{m} ; \boldsymbol{F}, 50 \mu \mathrm{m}$.
A sparse collection of $\mathrm{Nmb}$ cells was present dorsomedial to the prepositus nucleus. These Nmb neurons were located generally medial to the $\mathrm{C} 2$ neurons and dorsal to the $\mathrm{C} 3$ neurons and, unlike the latter, they did not express Pnmt (Fig. 3A). A second and much larger cluster of $\mathrm{Nmb}$ cells was located in the region of the central gray and posterodorsal tegmental nucleus medial to the locus ceruleus (Fig. $3 B$ ), from 5.63 to $5.41 \mathrm{~mm}$ caudal to bregma (coordinates after the corresponding plates in the atlas of Paxinos and Franklin, 2013) and did not express Th.

Parafacial Nmb cells are glutamatergic, non-catecholaminergic neurons that express Phox $2 b$

We noted that Nmb and Th cell bodies were non-overlapping in the parafacial region, an observation that was borne out by quantitative analysis of these multiplex in situ hybridization experiments: virtually none of the Nmb neurons expressed $T h$ (only 2/802 cells, counted in 3 mice; Figs. $1,3)$. By contrast, essentially all parafacial $\mathrm{N} m b$ neurons expressed Phox $2 \mathrm{~b}$, as indicated by eGFP staining in JX99 mice (99.6\%, 799/802 cells in 3 mice; Fig. 1). Likewise, every $N m b$ parafacial neuron contained transcripts for VGlut2 (Slc17a6; $613 / 613$ cells, counted in 2 mice), whereas none expressed Gad1 (796/796 cells, counted in 3 mice; Fig. 4). Based on these results, parafacial Nmb neurons meet precisely the criteria used previously to define the RTN cell group; specifically, they are non-catecholaminergic (i.e., TH-negative) neurons located in the parafacial region that coexpress Phox $2 b$ and VGlut2 mRNA (Stornetta et al., 2006; Goridis et al., 2010; Ramanantsoa et al., 2011; Ruffault et al., 2015).

These ISH data were further validated by RNA-Seq results from 105 single Phox2bexpressing (i.e., GFP-fluorescent) neurons 
collected from the parafacial region of JX99 mice. From this dataset, we excluded one cell for which the sequencing results were low quality ( $<650,000$ mapped reads). We also excluded six neurons that were clearly $\mathrm{C} 1$ neurons, because they expressed transcripts for catecholamine synthesizing enzymes at values much higher than found for those same genes in the remaining sample of 98 non-C1 neurons (median TPM: for Th, 1451 vs 0; for $D d c$, 114 vs 33.4; for $D b h, 422$ vs 0 ; and for Pnmt, 326 vs 0); importantly, and consistent with histochemical data, none of the C1 neurons were positive for $\mathrm{Nmb}$ (all $\mathrm{TPM}<20$ ). From the remaining 98 non-C1 neurons, we excluded samples that showed higher than expected levels of either Gad1 or Gad2 (TPM > 30; $n=8$ and $n=2$ ). Although it is formally possible that the presence of $\mathrm{Gad} 1 / \mathrm{Gad} 2$ represents true expression of these GABA-synthesizing enzymes in a minor subgroup of RTN neurons (Hayes et al., 2017), we think it is more likely to reflect contamination of these particular samples, a common concern in single-cell molecular studies and a conservative interpretation consistent with prior data designating RTN neurons as excitatory rather than inhibitory neurons (Bochorishvili et al., 2012; Holloway et al., 2015). That Gad1 mRNA was undetectable by in situ hybridization, but highly expressed in neighboring $N m b$-negative neurons, also supports this view (Fig. 4).
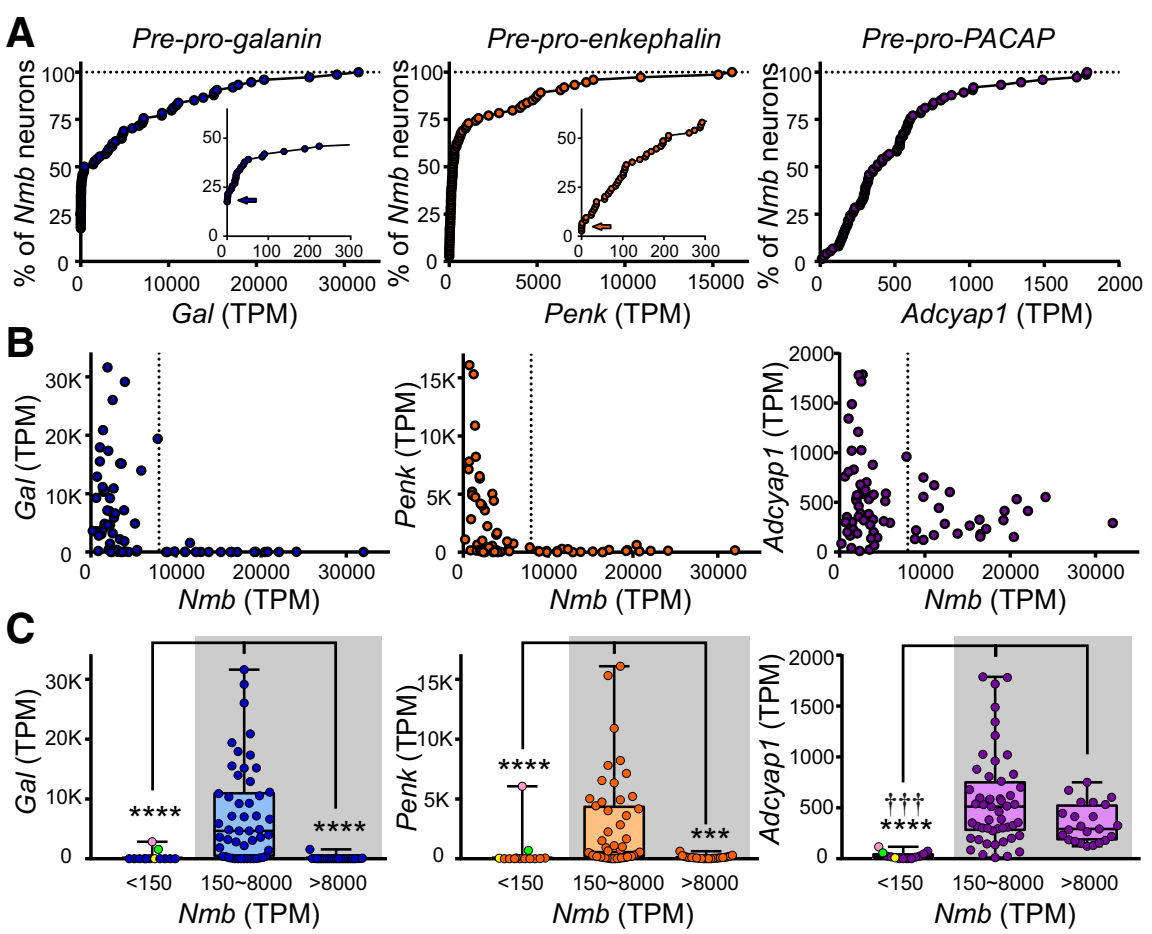

Figure 7. Transcript expression levels for Gal, enkephalin, and pituitary adenylate cyclase-activating peptide in Nmbexpressing RTN neurons. $\boldsymbol{A}$, Cumulative probability distributions of expression levels for the indicated neuropeptide transcripts in $\mathrm{Nmb}$-expressing neurons; the percentage of non-expressing neurons can be estimated from the $y$-intercept (TPM $=0$; insets for Gal and Penk, arrows). B, Transcript levels for Gal, Penk, and Adcyap1, relative to Nmb, in the same individual RTN neurons. C, Transcript expression levels for Gal, Penk, and Adcyap1 in Nmb-low (150< TPM < 8000) and Nmb-high (TPM > 8000) RTN neurons. Data from Phox2b-positive neurons that were below the operational threshold for consideration as Nmb-expressing RTN neurons (TPM < 150) are also depicted. Note that Gal and Penk expression is undetectable in the Nmb-high subpopulation of RTN neurons (TPM $>8000$ ); it is also virtually nonexistent in the Phox2b-positive, Nmb-negative neurons (two outliers are marked). ${ }^{* * * *} p<0.0001,{ }^{* * *} p<0.001$ versus Nmb-low RTN neurons $(150 \sim 8000)$; $\uparrow \dagger \uparrow p<0.001$ versus Nmb-negative neurons (TPM $<150$ ) by Kruskal-Wallis ANOVA.
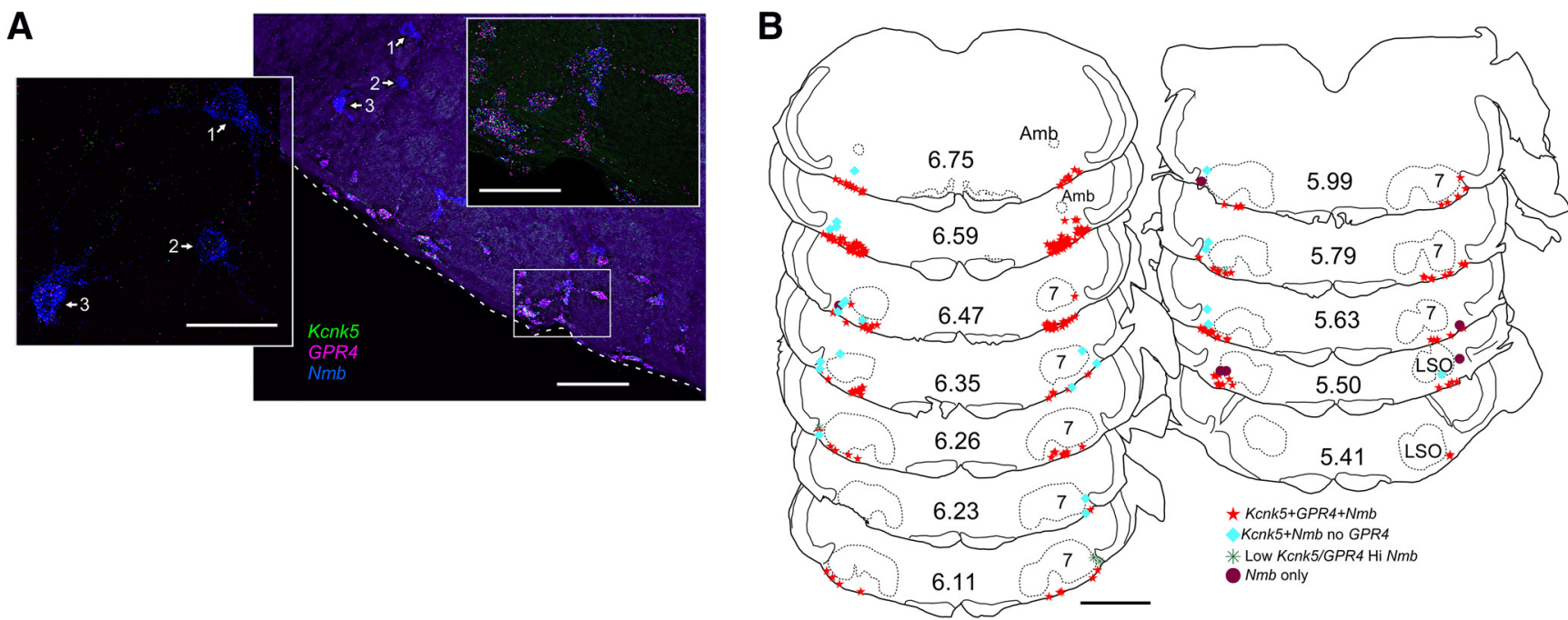

Figure 8. Most parafacial Nmb neurons express proton sensors Gpr4 and TASK-2 (encoded by Kcnk5). A, Photomicrograph of coronal section from caudal parafacial region (left side) showing transcripts for $\mathrm{Nmb}$ (blue), Gpr4 (magenta), and Kcnk5 (green). Inset to the left is an enlargement of relatively large cells (numbered 1, 2, and 3) that contain low levels of Kcnk5 and/or Gpr4 transcripts but high levels of Nmb. Inset to the right is an enlargement of the boxed area showing that most parafacial Nmb neurons express transcripts for both Gpr4 and Kcnk5. Note larger cells with high levels of $\mathrm{Nmb}$ transcripts and relatively low levels of Kcnk5/Gpr4 are located dorsal and lateral to the other Nmb neurons. Medial to the right, dorsal toward the top. Dashed white lines indicate ventral medullary surface. $\boldsymbol{B}$, Drawing of coronal sections through medulla/pons showing the distribution of $\mathrm{Nmb}$ neurons with $K$ cnk5 and Gpr4. Note the neurons with either low levels or no detectable Kcnk5/Gpr4 tend to be dorsal and lateral to the Nmb neurons that contain both of these proton sensors. Numbers in center of sections indicate $\mathrm{mm}$ behind bregma (after Paxinos and Franklin, 2013). Abbreviations as in Figure 1. Scale bars: $\boldsymbol{A}, 100 \mu \mathrm{m}$; left inset, $50 \mu \mathrm{m}$; right inset, $50 \mu \mathrm{m} ; \boldsymbol{B}, 1 \mathrm{~mm}$. 
A

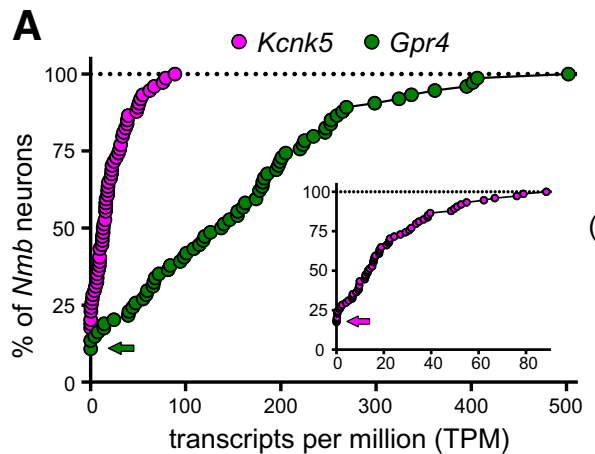

C
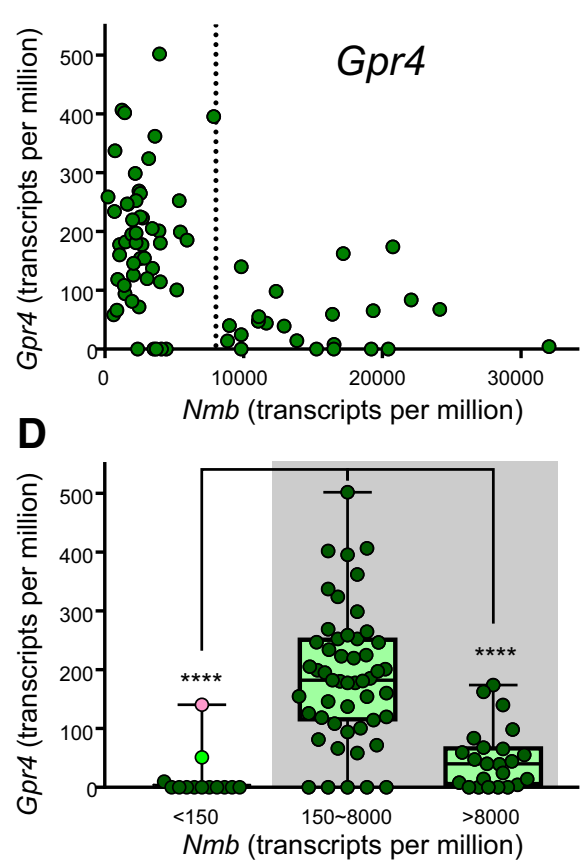

B
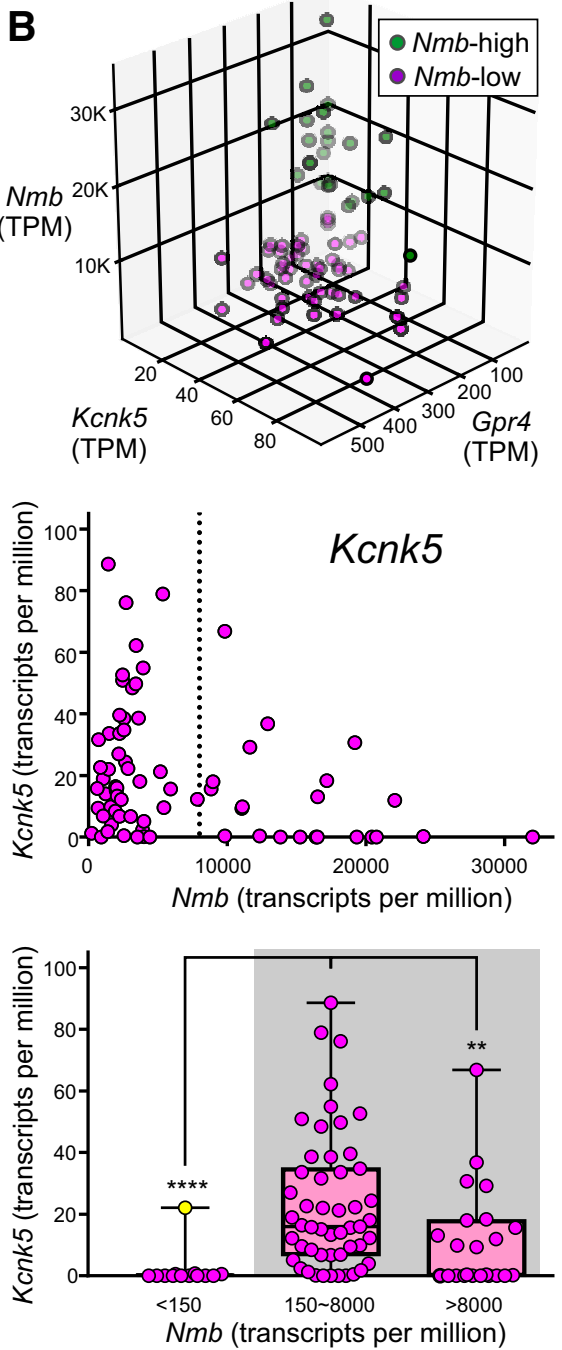

Figure 9. Gpr4/Kcnk5 transcript levels are lower in the Nmb-high subgroup of parafacial neurons. $A$, Cumulative probability distributions of expression levels for the indicated proton sensor in $N m b$-expressing neurons; the percentage of non-expressing neurons can be estimated from the $y$-intercept (see arrows; inset is expanded for Kcnk5). B, 3-D distribution of Gpr4, Kcnk5, and $\mathrm{Nmb}$ expression shows that within both $\mathrm{Nmb}$-high (green) and Nmb-low (purple) populations, a few parafacial neurons predominantly express higher levels of either Gpr 4 or Kcnk5. For example, see cells extending outward on the plane of the right rearmost wall (high Kcnk5, low Gpr4) or extending outward on the plane of the left rearmost wall (high Gpr4, low Kcnk5). C, Transcript levels for $G p r 4$ and $K c n k 5$ relative to $N m b$ in the same individual parafacial neurons. D, Transcript expression levels for Gpr 4 and $K c n k 5$ in Nmb-low (150 < TPM < 8000) and Nmb-high (TPM > 8000) RTN neurons. Data from cells that were below the operational threshold for consideration as Nmb-expressing RTN neurons (TPM < 150) are also depicted. Note that Gpr4 and Kcnk5 expression is significantly lower in the Nmb-high subpopulation of RTN neurons (TPM > 8000), by comparison to Nmb-low RTN neurons; it is also virtually nonexistent in the Phox2b-positive, Nmb-negative neurons (outliers are marked, color-coded as in Fig. 7). ${ }^{* * *} p<$ $0.0001,{ }^{* *} p<0.01$ versus Nmb-low RTN neurons $(150 \sim 8000)$ by Kruskal-Wallis ANOVA.

All of the remaining 88 neurons were positive for both Phox $2 b$ and VGlut2 mRNA (Slc17a6), and 75 showed appreciable levels of $\mathrm{Nmb}$ expression (Fig. $5 \mathrm{~A}$; operationally defined as TPM > $150)$. We expect that the small group of $N m b$-negative neurons $(n=13 ;$ TPM $<150)$ present in our GFP-targeted sample likely correspond to the population of Phox $2 b+, \mathrm{Nmb}-$ neurons encroaching on the dorsal and/or rostral boundaries of the RTN proper (Fig. 1C,D, green circles) because they present with a generally distinct neuropeptide and proton sensor phenotype (see Figs. $7 C, 9 D$ ). Among the larger group of $N m b$-expressing RTN neurons in our sample $(n=75), N m b$ transcript levels were widely variable (median: 3,523; range: 224-32,022), and appeared to represent two populations: $\sim 70 \%$ of the neurons were approximately normally distributed with low-to-moderate $\mathrm{Nmb}$ transcript levels
$(150<$ TPM $<8,000)$, whereas a clear inflection point in the cumulative probability plot at TPM $\sim 8,000$ revealed a separate subgroup of $\sim 30 \%$ of RTN neurons that express particularly high levels of $\mathrm{Nmb}$ (Fig. 5B).

A number of other transcriptomic features of individual $\mathrm{Nmb}$-expressing parafacial neurons are consistent with those expected for RTN neurons. For example, in developmental genetic analyses, the substance $\mathrm{P}$ receptor, NK1R, has been used to define RTN (Thoby-Brisson et al., 2009). Accordingly, we find expression of the cognate gene, Tacrl, in essentially all $N m b$-expressing neurons (Fig. $5 C, D$; in $97.3 \%$ of neurons, $n=73 / 75$; TPM median: 19.7; range: $0-98$ ). We also find varying levels of expression for other G-protein-coupled receptors that have been associated previously with RTN neurons (Mulkey et al., 2007; Lazarenko et al., 2011; Barna et al., 2016), as evident in the transcript distributions for the most prominent receptor subtypes in $\mathrm{Nmb}$ positive cells (Fig. $5 C, D$ ): the $5-\mathrm{HT}_{2 \mathrm{C}}$ receptor is universally expressed (Htr2c, TPM median: 51.1; range: 2-231); transcripts for the $\mathrm{P}_{2} \mathrm{Y}_{12}$ receptor are found at appreciable levels, albeit in only $\sim 40$ $50 \%$ of the neurons (P2ry12, TPM median: 0.7; range: $0-1065)$; and those for each of the orexin/hypocretin receptors are present in $\sim 75 \%$ of cells (Hcrtrl, TPM median: 23.0; range: $0-291$; Hcrtr2, TPM median: 40.1; range: $0-179$ ), with only $\sim 10 \%$ of neurons lacking either orexin receptor subtype. Conversely, these $\mathrm{Nmb}$ expressing neurons were virtually devoid of transcripts for the tryptophan hydroxylase enzymes (TPM $<10$ for Tph1 and Tph2; $n=75$ and $n=74)$ and the serotonin transporter (TPM $<10$ for Slc6a4; $n=75$ ); they were also negative for markers of inhibitory neurons, such as glycine transporter 2, GlyT2, and the GABA vesicular transporter, Vgat $($ TPM $<10$ for Slc6a5 and Slc32a1; $n=$ 73 and $n=75$ ).

In sum, our histochemical and transcriptomic analysis indicates that Phox $2 b+/ S l c 17 a 6+$ parafacial neurons that have characteristics of RTN neurons uniformly express $\mathrm{Nmb}$; this was not true of other Phox $2 b$-expressing neurons in the vicinity, such as those located dorsal and/or rostral to the RTN, or the C1 adrenergic neurons. A quantitative analysis of $\mathrm{Nmb}$ transcript levels revealed two subgroups of RTN neurons: a larger group $(\sim 70 \%)$ with low-to-moderate $\mathrm{Nmb}$ expression (henceforth $\mathrm{Nmb}$-low, TPM: $150 \sim 8000)$ and a smaller group $(\sim 30 \%)$ with much higher $N m b$ expression ( $N m b$-high, TPM $>8000)$. We next sought to determine whether these different $\mathrm{Nmb}$-expressing subpopulations were preferentially associated with other genes that had previously been identified in RTN neurons, or perhaps with distinct functional characteristics. 
Table 3. Cell counts for hypercapnia cases

\begin{tabular}{|c|c|c|c|c|c|c|c|c|c|}
\hline $\begin{array}{l}\text { Sex } \\
\text { Strain }\end{array}$ & $\begin{array}{l}\text { Female } \\
\text { C57 }\end{array}$ & $\begin{array}{l}\text { Female } \\
\text { C57 }\end{array}$ & $\begin{array}{l}\text { Female } \\
\text { C57 }\end{array}$ & $\begin{array}{l}\text { Female } \\
\text { JX99 }\end{array}$ & $\begin{array}{l}\text { Female } \\
\text { JX99 }\end{array}$ & $\begin{array}{l}\text { Male } \\
\text { C57 }\end{array}$ & $\begin{array}{l}\text { Male } \\
\text { C57 }\end{array}$ & Average \pm SEM & $\begin{array}{l}\text { Average \% Total } \\
\mathrm{Nmb} \pm \text { SEM }\end{array}$ \\
\hline \multicolumn{10}{|l|}{ Condition, $15 \% \mathrm{CO}_{2}$} \\
\hline Case & 22609 & 23205 & 26100 & 3409 & 3502 & J01 & $\mathrm{J} 03$ & & \\
\hline $\mathrm{Nmb}+\mathrm{Fos}+\mathrm{Gpr} 4$ & 135 & 234 & 141 & 100 & 73 & 73 & 66 & $117.4 \pm 22.5$ & $73.5 \pm 2.9$ \\
\hline $\mathrm{Nmb}+\mathrm{Gpr} 4$ no Fos & 9 & 20 & 21 & 8 & 15 & 2 & 4 & $11.3 \pm 2.8$ & $6.8 \pm 1.5$ \\
\hline Nmb + Gpr4-low no Fos & 13 & 14 & 13 & 5 & 3 & 1 & 4 & $7.6 \pm 2.1$ & $4.3 \pm 0.8$ \\
\hline Nmb no Gpr4 no Fos & 28 & 27 & 37 & 38 & 28 & 9 & 12 & $25.6 \pm 4.2$ & $16.7 \pm 2.5$ \\
\hline Total Nmb & 185 & 295 & 212 & 151 & 109 & 85 & 86 & $160.4 \pm 29.0$ & \\
\hline No. of sections & 7 & 11 & 14 & 6 & 6 & 6 & 6 & $8 \pm 1.2$ & \\
\hline \multicolumn{10}{|l|}{ Condition, $21 \% \mathrm{O}_{2}$} \\
\hline Case & 26101 & 22305 & 22503 & 3407 & 3408 & $\mathrm{~J} 02$ & $\mathrm{~J} 00$ & & \\
\hline $\mathrm{Nmb}+\mathrm{Fos}+\mathrm{Gpr} 4$ & 2 & 7 & 8 & 1 & 0 & 2 & 0 & $2.9 \pm 1.2$ & $1.5 \pm 0.6$ \\
\hline $\mathrm{Nmb}+\mathrm{Gpr} 4$ no Fos & 163 & 182 & 182 & 122 & 73 & 57 & 36 & $116.4 \pm 23.2$ & $78.0 \pm 2.2$ \\
\hline $\mathrm{Nmb}+$ Gpr4-low no Fos & 15 & 14 & 3 & 0 & 1 & 5 & 0 & $5.4 \pm 2.4$ & $3.0 \pm 1.2$ \\
\hline Nmb no Gpr4 no Fos & 54 & 33 & 32 & 35 & 13 & 17 & 7 & $27.3 \pm 6.1$ & $18.0 \pm 1.5$ \\
\hline Total Nmb & 234 & 226 & 225 & 158 & 87 & 81 & 43 & $150.6 \pm 30.4$ & \\
\hline No. of sections & 10 & 10 & 12 & 6 & 6 & 6 & 5 & $7.9 \pm 1.0$ & \\
\hline \multicolumn{10}{|l|}{ Condition, $15 \% \mathrm{CO}_{2}$} \\
\hline Case & 23205 & & & & & $\mathrm{~J} 01$ & & & \\
\hline $\mathrm{Nmb}+\mathrm{Fos}+\mathrm{TASK}-2$ & 180 & & & & & 213 & & $196.5 \pm 16.5$ & $78.6 \pm 3.6$ \\
\hline $\mathrm{Nmb}+$ TASK-2 no Fos & 29 & & & & & 44 & & $36.5 \pm 7.5$ & $14.4 \pm 1.1$ \\
\hline Nmb no TASK-2 no Fos & 10 & & & & & 15 & & $12.5 \pm 2.5$ & $4.9 \pm 0.4$ \\
\hline Total Nmb & 219 & & & & & 284 & & $251.5 \pm 32.5$ & \\
\hline No. of sections & 12 & & & & & 12 & & 12 & \\
\hline
\end{tabular}

C57, C57BI6/J; Gpr4, G-protein-coupled receptor 4; JX99, Phox2b-eGFP BAC transgenic; TASK-2, potassium channel subfamily K member 5. Nmb + Gpr4-low refers to cells with Nmb and very low levels of Gpr4 transcript. No attempt was made to distinguish $\mathrm{Nmb}$-high or Nmb-low cells in these counts.

\section{RTN Nmb neurons express additional neuropeptides pre-pro-galanin and pre-pro-enkephalin}

Gal could be identified by ISH in $70 \pm 2 \%$ of $N m b$-expressing RTN neurons $(n=4$ mice; Fig. $6 A, B, E, F)$. Gal $/ N m b+$ neurons were scattered among the $N m b$ neurons devoid of $\mathrm{Gal}$ mRNA without discernible rostrocaudal or mediolateral clustering. The percentage of RTN Gal+ neurons was slightly higher than our previous estimate of $50 \%$ in the rat (Stornetta et al., 2009). This could be due to either species differences or the use of the more sensitive RNAscope technique in the current study. When assessed by single-cell RNA-Seq, Gal was detected in $82.7 \%$ of the $N m b$-expressing neurons $(n=62 / 75)$. However, there was marked variability in Gal expression levels in individual neurons (median TPM: 417; range: $0-31,618$ ). Notably, although Gal was not universally expressed in the $N m b$-low population of RTN neurons (TPM $<8000$ ), it was always extremely low or absent within the RTN subpopulation expressing the highest levels of Nmb (TPM > 8000; Fig. 7).

A similar result was obtained with Penk (Fig. 6A,B). By ISH, Penk transcripts were observed in $67 \pm 8 \%$ of parafacial $N m b$ neurons throughout the RTN region, with no obvious preferential localization along its rostrocaudal or mediolateral extent $(n=$ 4 mice). By single-cell RNA-Seq, Penk transcripts could be detected in $97.3 \%$ of $N m b$-expressing neurons $(n=73 / 75)$. As with Gal, a broad range of Penk expression was observed across individual $N m b$-expressing neurons, although with a lower peak level of expression (median TPM: 212; range: 0-16,089). Also similar to $\mathrm{Gal}$, a striking inverse correlation was observed between Penk and $N m b$ expression, such that the highest $N m b$-expressing neurons were always essentially devoid of Penk transcripts (Fig. 7).

\section{Adcyap1}

By ISH, Adcyap1 transcripts were present in a large proportion of the RTN $N m b$ neurons ( $88 \pm 4 \%, n=4$ ), again distributed without discernible clustering throughout the nucleus (Fig. 6C,D). By RNA-Seq, Adcyap1 transcripts could be detected in all Nmb- expressing RTN neurons ( $n=75 / 75)$. The overall transcript levels were lower than for Gal and Penk (median TPM: 387; range: 121787) and, unlike with Gal and Penk, Adcyap1 expression was clearly evident even in cells with the highest levels of $\mathrm{Nmb}$ (Fig. 7).

It is also worth mentioning that these neuropeptides were rarely detected in the group of non- $\mathrm{C} 1$, Phox $2 b$-positive neurons with $N m b$ expression below our operational threshold (i.e., with TPM $<150, n=13$ ), which were judged to represent a distinct population (Fig. 7C). Interestingly, however, the two neurons in this group with appreciable amounts of Gal (TPM: 2846, 1573), Penk (TPM: 6062, 700), and Adcyap1 transcripts (TPM: 117, 57) were also positive for Gpr4 (see below), suggesting that they may indeed be RTN neurons, but at the lower extreme of Nmb expression. Even so, the neuropeptide expression data from these outliers are consistent with the general observation that Gal and Penk expression is limited to the Nmb-low group of RTN neurons.

Collectively, this assessment of neuropeptide expression is consistent with the suggestion that RTN comprises phenotypically distinct subgroups of $N m b$-expressing neurons that can be differentiated by either high or low levels of $N m b$ expression.

\section{Most RTN Nmb neurons express Kcnk5 and Gpr4}

A large but still unspecified proportion of RTN neurons are intrinsically sensitive to $\mathrm{CO}_{2} / \mathrm{H}^{+}$; this property is mediated in large part by either (or both) of two distinct $\mathrm{pH}$ sensors: TASK-2 (encoded by Kcnk5) and Gpr4. Indeed, by ISH, we found that a major fraction of parafacial $N m b$ neurons contained transcripts for Kcnk5 (92 $\pm 3 \%, n=$ 6 mice) or Gpr4 ( $82 \pm 1 \%, n=25$ mice; Fig. 8). However, the neurons that contained high levels of $\mathrm{Nmb}$ usually had little or no detectable Gpr4 or Kcnk5 (Fig. 8A). Nmb-high neurons were rarely found on the ventral medullary surface; they were almost always more dorsal (Fig. $8 A$ ) and tended to be more lateral to the main group of $\mathrm{Nmb}$ cells in more rostral locations (Fig. 8B; especially at levels rostral to 6.35).

We noticed that many of the $N m b$-high expressing neurons appeared to be larger than the $N m b$-low cells (compare Figs. $6 E$, $8 A, 10 A, C$ ) and measured in 3 JX99 mice the cross sectional soma 

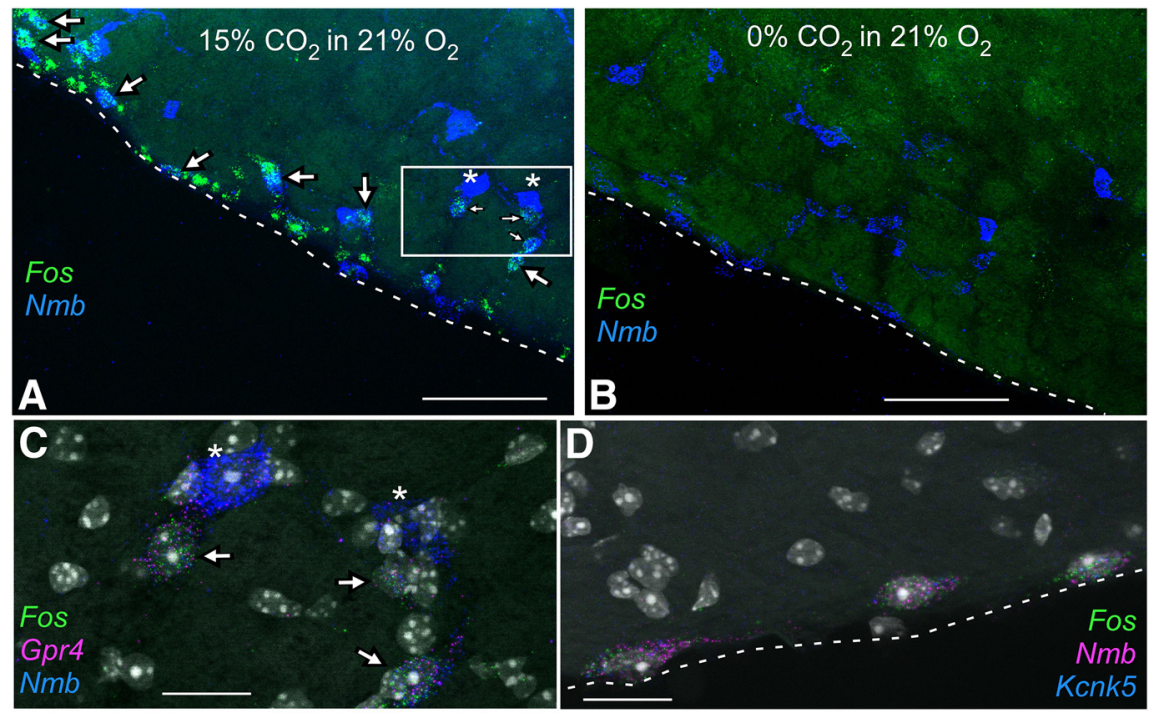

$$
\begin{aligned}
& \quad \star F o s+N m b+G p r 4 \\
& N m b \text { only } \\
& N m b+\text { Gpr4 no Fos }
\end{aligned}
$$
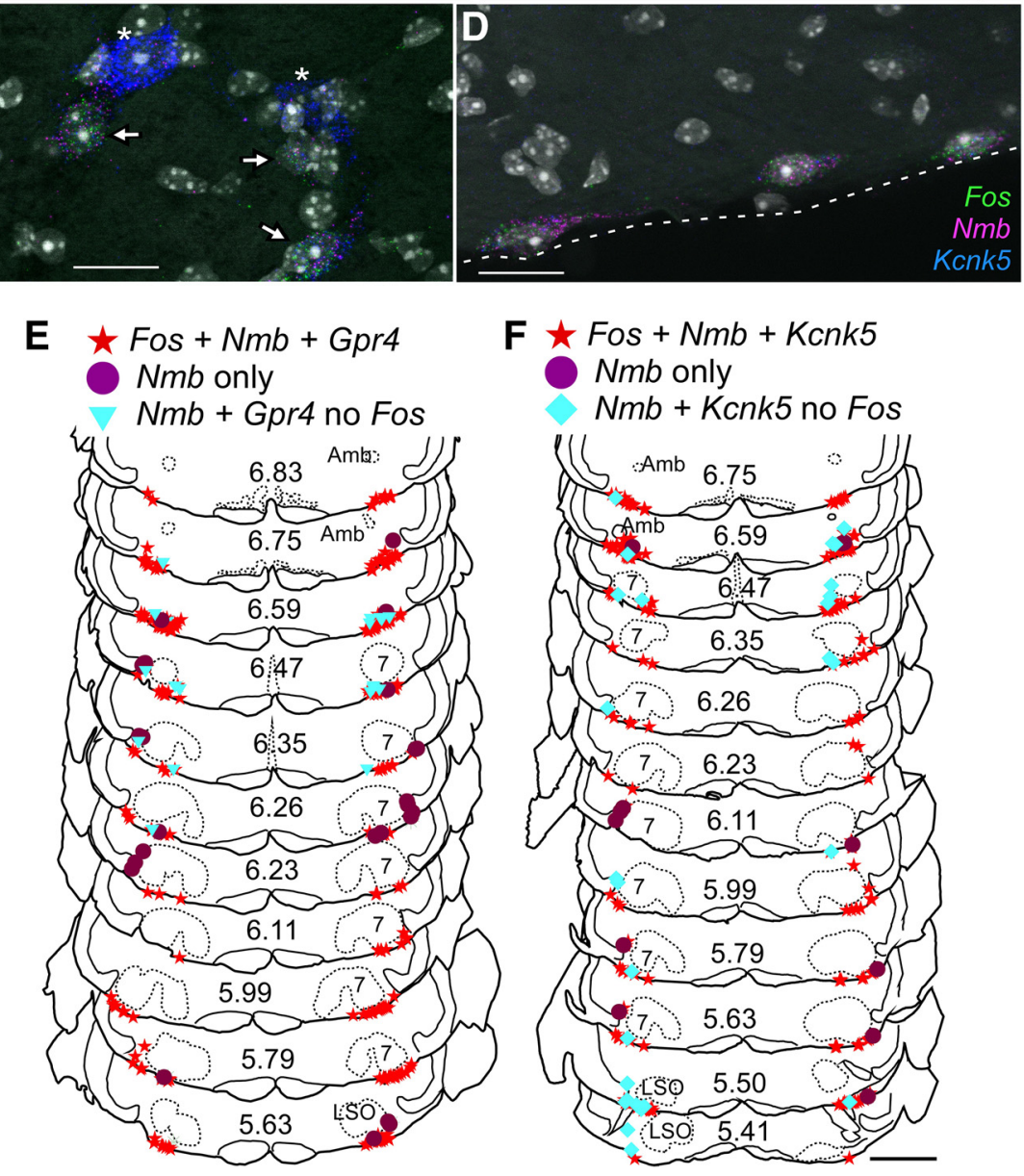

Figure 10. RTN Nmb neurons with proton sensors Gpr4 and TASK-2 express Fos in mice exposed to hypercapnia. $\boldsymbol{A}, \boldsymbol{B}$, Photomicrographs of coronal section in caudal RTN showing transcripts for Fos (green) and $\mathrm{Nmb}$ (blue) in mouse exposed to $15 \% \mathrm{CO}_{2}$ in $21 \% \mathrm{O}_{2}(\boldsymbol{A})$ or $21 \% \mathrm{O}_{2}(\boldsymbol{B})$. Many neurons express Fos under hypercapnia ( $\boldsymbol{A}$, arrows). Note that large neurons with high levels of $\mathrm{Nmb}$ transcripts in $(\boldsymbol{A})$ indicated by stars do not express Fos. $\boldsymbol{C}$, Enlargement of boxed area in $\boldsymbol{A}$ showing neurons expressing transcripts for Nmb (blue), Gpr4 (magenta), and Fos (green). Neurons indicated by stars express high levels of Nmb but low or undetectable levels of Gpr4 and do not express Fos. DAPI stain in white/gray. D, Photomicrograph of neurons expressing transcripts for $\mathrm{Nmb}$ (magenta), $K c n k 5$ (blue), and Fos (green) from mouse exposed to $15 \% \mathrm{CO}_{2}$. Dashed lines in $\boldsymbol{A}, \boldsymbol{B}$, and $\boldsymbol{D}$ represent the ventral medullary surface. $\boldsymbol{E}, \boldsymbol{F}$, Drawing of transverse sections through the medulla and pons showing the distribution of $\mathrm{Nmb}$ neurons with $K c n k 5(\boldsymbol{E})$ or Gpr $4(\boldsymbol{F})$ and Fos after exposure to $15 \% \mathrm{CO}_{2}$. The Nmb neurons that do not express Fos tend to be dorsal and lateral to the $\mathrm{Nmb}$ neurons that are activated by hypercapnia. Numbers in center of sections indicate $\mathrm{mm}$ behind bregma (Paxinos and Franklin, 2013). Abbreviations as in Figure 1. Scale bars: $\boldsymbol{A}, 100 \mu \mathrm{m} ; \boldsymbol{B}, 100 \mu \mathrm{m} ; \boldsymbol{C}, 20 \mu \mathrm{m} ; \mathbf{D}, 20 \mu \mathrm{m} ; \boldsymbol{E}, 1 \mathrm{~mm}$.

area of GFP-labeled cells containing $\mathrm{Nmb}$ and Gpr4 transcripts (because the eGFP fills the cytoplasm and allows accurate soma tracing). Indeed, the $N m b$-high cells had a significantly larger soma area $\left(153.4 \mu \mathrm{m}^{2} ; n=21\right.$; range 94.2-390.2) than the $N m b$-low cells $\left(74.4 \mu \mathrm{m}^{2} ; n=60\right.$; range 35.1-169.5) compared with a one-tailed Mann-Whitney $U(U=48 ; p<0.001)$.

By single-cell RNA-Seq (Fig. 9), we found that Gpr4 was detectable in $89.3 \%$ of $N m b$-expressing RTN neurons $(n=67 / 75)$ and was the highest expressed of all G-protein-coupled receptors in those cells (median TPM: 140.2; range: $0-502$; compare with Fig. 5C,D). For Kcnk5, expression could also be detected in a large fraction of $\mathrm{Nmb}$-expressing RTN neurons $(82.7 \% ; n=62 / 75)$, although transcript levels were lower overall than for Gpr4 (median TPM for Kcnk5: 14; range: 0-89).

Most RTN neurons expressed both Gpr4 and Kcnk5, but some had high Gpr4 expression and little to no Kcnk5 expression whereas others showed high Kcnk5 expression and little to no Gpr4 expression (Fig. 9B). The neurons that showed a strong preferential expression of either Gpr4 or Kcnk5 likely correspond to the subgroups of previously characterized cells for which one of those genes was required for pH-sensitivity (Wang et al., 2013b; Kumar et al., 2015). In addition, consistent with in situ hybridization results, there was a clear relationship between Gpr4 or Kcnk5 levels and Nmb expression: the subgroup of RTN neurons with the highest levels of $N m b$ transcripts had correspondingly lower levels of Gpr4 and Kcnk5 (Fig. 9C,D).

As mentioned earlier, the $N m b$ threshold (TPM < 150) was generally effective for differentiating the RTN population of neurons from other nearby GFP-labeled cells; indeed, most of this other population was also negative for Gpr4 and Kcnk5, with the notable exception of two Gpr4expressing neurons (also Gal- and Penk-positive; Fig. 7C) and one Kcnk5-expressing neuron. Although these outliers would be at the lower extreme of $N m b$ expression in this sample of RTN neurons, they nevertheless adhere to the general principle that $\mathrm{Nmb}$-low group of RTN neurons are relatively more likely to express Gpr4 and Kcnk5.

\section{Most RTN Nmb neurons are activated by hypercapnia but unresponsive to hypoxia}

We used Fos expression as a readout of neuronal activation to examine whether the quantitative differences in Gpr4 and/or Kcnk5 expression between $\mathrm{Nmb}$ high and $N m b$-low subgroups described above might yield corresponding functional differences in effects of $\mathrm{CO}_{2}$ on RTN neurons in vivo. In mice exposed to hypercapnia for 35 $\min \left(15 \% \mathrm{FiCO}_{2}, 21 \% \mathrm{FiO}_{2}\right.$, balance $\left.\mathrm{N}_{2}\right)$, Fos expression was observed in most RTN Nmb neurons ( $74 \pm 14 \%, n=7$; Table 3; Fig. 10), whereas in control animals exposed to normoxia $\left(21 \% \mathrm{FiO}_{2}\right.$, balance $\left.\mathrm{N}_{2}\right)$ this percentage was very low $(1.5 \pm$ $0.5 \%, n=7$; Table 3; Fig. $10 B)$.

The vast majority of parafacial neurons that contained both $N m b$ and moderate levels of Gpr4 transcripts also contained Fos 
Table 4. Bilateral cell counts for hypoxia cases

\begin{tabular}{|c|c|c|c|c|c|c|c|}
\hline $\begin{array}{l}\text { Sex } \\
\text { Strain }\end{array}$ & $\begin{array}{l}\text { Male } \\
\text { JX99 }\end{array}$ & $\begin{array}{l}\text { Male } \\
\text { JX99 }\end{array}$ & $\begin{array}{l}\text { Male } \\
\text { JX99 }\end{array}$ & $\begin{array}{l}\text { Male } \\
\text { C57 }\end{array}$ & $\begin{array}{l}\text { Male } \\
\text { C57 }\end{array}$ & Average \pm SEM & $\begin{array}{l}\text { Average } \\
\% \text { Total } \\
\mathrm{Nmb} \pm \mathrm{SEM}\end{array}$ \\
\hline \multicolumn{8}{|l|}{ Condition, $8 \% \mathrm{O}_{2}$} \\
\hline $\mathrm{Nmb}+\mathrm{F}_{0 \mathrm{~S}}+\mathrm{Gpr} 4$ & 13 & 2 & 13 & 10 & 9 & $9.4 \pm 2.0$ & $3.6 \pm 0.7$ \\
\hline $\mathrm{Nmb}+\mathrm{Gpr} 4$ no Fos & 178 & 156 & 180 & 187 & 195 & $179.2 \pm 6.5$ & $71.6 \pm 1.5$ \\
\hline Nmb Gpr4-low no Fos & 11 & 5 & 6 & 14 & 17 & $10.6 \pm 2.3$ & $4.2 \pm 0.8$ \\
\hline Nmb only & 52 & 45 & 72 & 46 & 44 & $51.8 \pm 5.2$ & $20.6 \pm 1.7$ \\
\hline Total Nmb & 254 & 208 & 271 & 257 & 265 & $251.0 \pm 11.2$ & \\
\hline No. of sections & 12 & 12 & 10 & 12 & 12 & $11.6 \pm 0.4$ & \\
\hline \multicolumn{8}{|l|}{ Condition, $21 \% \mathrm{O}_{2}$} \\
\hline Case & & 7010 & 6494 & 25101 & 25103 & & \\
\hline $\mathrm{Nmb}+\mathrm{Fos}+\mathrm{Gpr} 4$ & & 1 & 6 & 6 & 1 & $3.5 \pm 1.3$ & $1.3 \pm 0.4$ \\
\hline $\mathrm{Nmb}+\mathrm{Gpr} 4$ no Fos & & 217 & 229 & 193 & 114 & $188.25 \pm 23.1$ & $72.3 \pm 2.2$ \\
\hline Nmb Gpr4-low no Fos & & 18 & 8 & 8 & 11 & $11.3 \pm 2.1$ & $4.5 \pm 0.8$ \\
\hline Nmb only & & 59 & 45 & 75 & 44 & $55.8 \pm 6.5$ & $21.9 \pm 2.0$ \\
\hline Total Nmb & & 295 & 288 & 282 & 170 & $258.8 \pm 26.6$ & \\
\hline No. of sections & & 12 & 12 & 12 & 10 & $11.5 \pm 0.4$ & \\
\hline
\end{tabular}

C57, (57Bl6/J; Gpr4, G-protein-coupled receptor 4; JX99, Phox2b-eGFP BAC transgenic. Nmb only refers to cells with $\mathrm{Nmb}$ transcripts with no Fos and no Gpr4 transcripts.

mRNA in mice exposed to hypercapnia ( $91 \pm 2 \%$; $n=7$; Table 3; Fig. 10). Notably, however, the $N m b$ neurons that contained little or no detectable Gpr4 mRNA (Figs. 8A, 9) did not express Fos after $\mathrm{CO}_{2}$ exposure $(0 / 232 \mathrm{Nmb}+$ Gpr4-low cells positive for Fos mRNA counted across 7 mice; Table 3; Fig. $10 A, C)$. The tissue distribution of the $\mathrm{CO}_{2}$-activated (Fos + ) parafacial $\mathrm{Nmb}$ neurons was the same as that of the $N m b$ neurons that contained both Gpr4 and Kcnk5 mRNA (compare Figs. $8 B, 10 E$ ). By contrast, the $\mathrm{CO}_{2}$-insensitive (Fos-) $\mathrm{Nmb}$ neurons were located dorsal and generally lateral to the $\mathrm{CO}_{2}$ responsive cells, with tendency toward being more lateral, particularly in the more rostral areas of RTN. A similar pattern of Fos expression was noted in two of the hypercapnia cases in which alternate sections were hybridized with Kcnk5 probe (i.e., Fos expression was primarily localized to Kcnk5-expressing RTN neurons; Fig. 10 D, F; Table 3).

In five male mice exposed to hypoxia $\left(8 \% \mathrm{FiO}_{2}\right)$ for $35 \mathrm{~min}$, very few Nmb neurons expressed Fos (3.6 $\pm 0.7 \%$; Table 4). As in the case for hypercapnia, none of the $N m b$-only (i.e., without Kcnk5 or Gpr4 ) cells expressed Fos in animals exposed to hypoxia $(0 / 259 \mathrm{Nmb}$-only cells counted in 5 mice). As expected, all mice showed a sharp increase in sighing behavior during hypoxia compared normoxia $\left(21 \% \mathrm{FiO}_{2}: 0.7 \pm 1.3\right.$ sighs $/ \mathrm{min}, n=5 ; 8 \% \mathrm{FiO}_{2}$ : $33.3 \pm 3.5$ sighs $/ \mathrm{min}, n=5$; unpaired $t=8.8, p<0.0001)$.

\section{Parafacial $\mathrm{Nmb}$ neurons in the rat}

We used a rat-specific probe (Table 1) to examine the distribution of $N m b$ mRNA in three adult male Sprague Dawley rats, confining our observations to the rostral medulla and pons. As in mice, $N m b$ cells were abundant in the parafacial region but, unlike in mice, they were also present within the ventromedial medulla oblongata and adjacent portions of the pons (Fig. 11A).

The Nmb neurons located in the parafacial region contained Phox $2 b$ transcripts, whereas those located more medially did not (Fig. $11 B-E$ ). The two groups were adjoining, but essentially nonoverlapping (Fig. 11A). As in mice, none of the $N m b$ neurons were TH-immunoreactive (data not shown). The distribution of the $\mathrm{Nmb}+/$ Phox $2 b+$ neurons was very similar to that of the mouse (compare Figs. 1, 11) and seemed virtually identical to that of the neurons previously defined as RTN in rats based on coexpression of VGlut 2 mRNA and Phox $2 \mathrm{~b}$ and absence of TH (Stornetta et al., 2006). Like previously defined RTN neurons, the cluster of $\mathrm{Nm} b+/$ Phox $2 b+$ neurons extended from a level $\sim 500 \mu \mathrm{m}$ cau- dal to the facial motor nucleus to the exit point of the seventh nerve (Fig. 11A). Based on cell counts performed in two animals using a one-in-six series of $30 \mu \mathrm{m}$ sections, and after Abercrombie correction, the rat contains $\sim 1910 \mathrm{Nmb}+/$ Phox $2 b+$ parafacial neurons, a number virtually identical to the cell population that we previously defined as RTN in this species based on anatomical location, coexpression of Phox $2 b$ and VGlut2, and lack of TH.

\section{Discussion}

The principal new findings are as follows. A single marker, $\mathrm{Nmb}$ mRNA, identifies the RTN, a population of $\sim 700$ parafacial neurons that could be definitively identified previously only by using a combination of several markers (expression of Phox2b, VGlut2, NK1R, and absence of catecholaminergic and other markers). At least $80 \%$ of RTN neurons contain transcripts coding for one or both proton receptors, Kcnk5 and Gpr4, and most of these neurons express Fos mRNA in mice exposed to hypercapnia but not hypoxia. We conclude from these observations that RTN consists mostly of $\mathrm{CO}_{2}$-sensitive chemoreceptors, and that $\mathrm{Nmb}$ mRNA identifies these chemoreceptors with $>75 \%$ accuracy. A subset of RTN neurons ( $\sim 20-30 \%)$ contain extremely high levels of $N m b$ mRNA, low to undetectable levels of Gpr4 and Kcnk5 transcripts, and typically lack two additional pre-propeptide genes (Penk, $\mathrm{Gal}$ ) that are variably expressed by other RTN neurons. These $\mathrm{Nmb}$-high RTN neurons are typically larger in size, do not respond to either hypercapnia or hypoxia, and are probably not chemoreceptors. Transcript levels determined by single-cell RNA-seq varied considerably from cell to cell (by 1-2 orders of magnitude). In several instances ( $\mathrm{Nmb}, \mathrm{Gal}$, Penk, Kcnk5, and Gpr4) this variability could be confirmed by ISH, at least in a semiquantitative sense, suggesting considerable phenotypic variability even in this small population of neurons. Finally, $\mathrm{Nmb}$ is also a marker of RTN in rats.

\section{$N m b$ mRNA: a diagnostic marker of RTN in mice}

Phox $2 b$ and VGlut2 transcripts were detectable in essentially all $N m b$ neurons located in the parafacial region of the mouse. These Nmb neurons did not express Th or Gad1/Gad2. In this region, $N m b$ transcripts are expressed by neurons that have all the phenotypical characteristics that have been used to define the RTN (i.e., presence of Phox 2 b, VGlut2, and NK1 receptors; widespread expression of Gpr4 and Kcnk5; and absence of Th, Tph1 or Tph2, Gad1 or Gad2, GlyT2, and Vgat; Stornetta et al., 2006; Goridis et al., 2010; Ramanantsoa et al., 2011; Guyenet and Bayliss, 2015; Ruffault et al., 2015). The number of $N m b$ neurons counted in the present study $(\sim 665)$ is smaller than our prior estimates of RTN cells based only on eGFP expression (as a proxy for Phox 2b) in the parafacial area in Phox2b::eGFP mice (787; Lazarenko et al., 2009) but still within the range of the number of neurons defined as RTN by genetic lineage analysis ( $\sim 600$ :ThobyBrisson et al., 2009; 700-800: Ramanantsoa et al., 2011). In light of these observations, we conclude that $N m b$ is a reliable single marker of the neuronal population previously defined as RTN based on combinatorial neurochemical and developmental criteria (Dubreuil et al., 2008; Thoby-Brisson et al., 2009; Guyenet et al., 2016).

In rats, $N m b$ transcripts also identify RTN but, in this species, $\mathrm{Nmb}$ is also expressed by a separate group of Phox2b-negative neurons located in the ventromedial medulla oblongata. The two populations are adjacent but overlap very little. Thus, $\mathrm{Nmb}$ expression should also serve as a useful marker of RTN in rat, although coexpression of Phox $2 \mathrm{~b}$ and $N m b$ would provide added precision. $N m b$ identifies the RTN in both rats and mice suggest- 

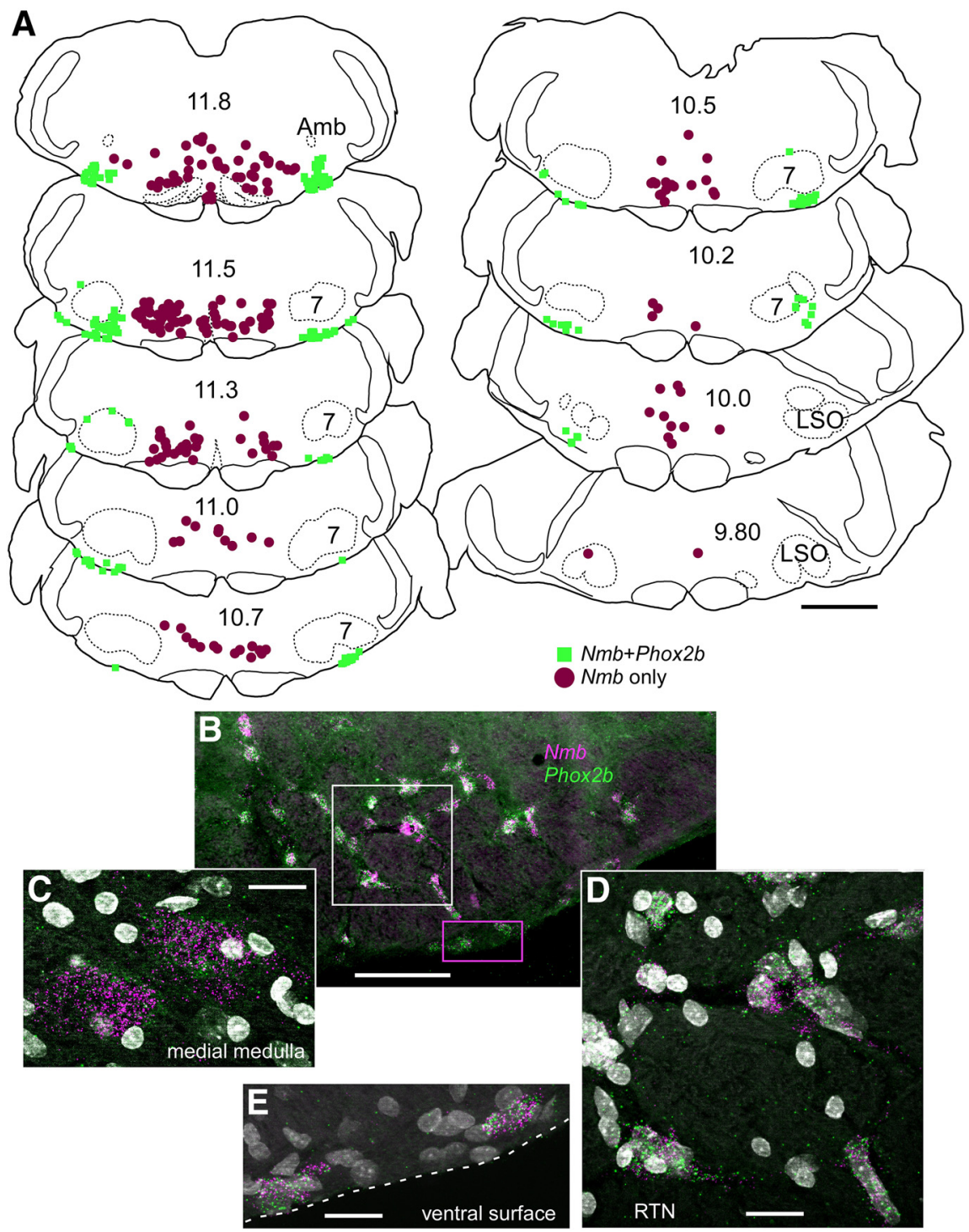

Figure 11. In rats Nmb transcripts are present both in RTN and in the adjacent medial reticular formation. $\boldsymbol{A}$, Drawing of coronal sections through medulla and caudal pons of rat showing the distribution of neurons with $N m b$ transcripts, with or without $P$ hox $2 b$ transcripts. As in the mouse, $\mathrm{Nmb}+$ Phox $2 b$ neurons delineate the RTN. However, a large separate population of $N m b$ neurons is located more medially in rat. Numbers in center of sections indicate mm behind bregma (after Paxinos and Watson, 2005). Abbreviations as in Fig. 1. B, Photomicrograph of coronal section in caudal RTN showing transcripts for Nmb in magenta and Phox $2 b$ in green. DAPI stain is white/gray. Medial to the left, dorsal toward the top. C, Photomicrograph from midline region where Phox $2 b$ is not expressed in $N m b$ neurons. $\boldsymbol{D}$, Enlargement of white dashed box from $\boldsymbol{B}$. Note coexpression of $N m b$ with Phox $2 b$ transcripts. $\boldsymbol{E}$, Enlargement of magenta dashed box in $\boldsymbol{B}$ showing cells expressing both Phox $2 b$ and $N m b$ transcripts. Scale: $\boldsymbol{A}, 500 \mu \mathrm{m}$. Scale bars: $A, 1 \mathrm{~mm} ; \boldsymbol{B}, 100 \mu \mathrm{m} ; \boldsymbol{C}-\boldsymbol{E}, 20 \mu \mathrm{m}$

ing that it could also be a useful marker of the human RTN (Rudzinski and Kapur, 2010).

\section{The majority of RTN neurons are central} respiratory chemoreceptors

Although the $\mathrm{CO}_{2} / \mathrm{H}^{+}$sensitivity of RTN neurons is likely enhanced by astrocyte-dependent paracrine mechanisms (Gourine et al., 2005, 2010), it is in large measure a cell-autonomous response to protons (Guyenet et al., 2016). This view is based on two key observations. RTN neurons are activated by $\mathrm{CO}_{2} / \mathrm{H}^{+}$ after complete isolation (Wang et al., 2013a) and both their $\mathrm{pH}$ sensitivity in vitro and the central respiratory chemoreflex require the expression by RTN neurons of proton sensors Gpr4 and TASK-2 (Gestreau et al., 2010; Wang et al., 2013b; Kumar et al., 2015). We show here that Gpr4 and Kcnk5 are usually coexpressed by RTN neurons. However, we also found cells in which one of those genes was preferentially expressed, likely corresponding to the subset of RTN neurons that only require Gpr4 or TASK-2 for their pH sensitivity (Wang et al., 2013b; Kumar et al., 2015).

We also found that $\sim 75 \%$ of RTN $\mathrm{Nmb}$ neurons in mice expressed Fos after exposure to hypercapnia $\left(15 \% \mathrm{FiCO}_{2}\right)$. This high level of $\mathrm{CO}_{2}$ stimulus, notwithstanding the limitations of Fos as a measure of neuronal activation, is likely to have revealed close to the true fraction of chemosensitive RTN neurons. Fewer RTN neurons $(\sim 35 \%)$ express Fos in mice exposed to $8 \% \mathrm{FiCO}_{2}$ (Kumar et al., 2015; Shi et al., 2016). Subsets of RTN neurons, such as those that elicit active expiration (Marina et al., 2010; Burke et al., 2015) probably have a high threshold of activation by $\mathrm{CO}_{2}$. Importantly, all the Fos + RTN neurons contained Gpr4 and Kcnk5 mRNA whereas these transcripts were generally undetectable in the small subset of RTN neurons that did not respond to $\mathrm{CO}_{2}$. The $\mathrm{CO}_{2}$-activated neurons did not express Fos after hypoxia. Using loss of function optogenetics, we previously demonstrated that the RTN neurons that drive breathing are silenced during hypoxia because of the accompanying respiratory alkalosis (Basting et al., 2015; Guyenet et al., 2016). Activation by hypercapnia and inhibition by hypoxia (as a result of the respiratory alkalosis) are responses that are expected from central respiratory chemoreceptors in intact unanesthetized mammals.

The Nmb neurons that did not detectably respond to hypercapnia typically expressed the highest levels of Nmb. Their cell bodies had a larger cross-sectional area, and tended to be located dorsal and lateral to the main cluster of RTN neurons. The function of these neurons is unknown, but they could be the $\sim 200 \mathrm{Nmb}$ neurons identified by Li et al. (2016) in the parafacial region of an Nmb-eGFP mouse that were implicated in Nmb-mediated sighing.

\section{RTN peptides}

In addition to $\mathrm{Nmb}$, mouse RTN neurons express Gal, Penk, and Adcyap 1 transcripts. The concentration of Gal and Penk transcripts was negatively correlated with $N m b$ levels. In particular, both Gal and Penk mRNA levels were low to undetectable in the $\mathrm{Nmb}$-high neurons. Adycap1 transcripts were also detected in nearby catecholaminergic neurons and facial motor neurons. Most propeptides can be processed into several bioactive transmitters. Galanin and Neuromedin B are presumably produced and used as transmitters by RTN neurons because their terminals are immuno- 


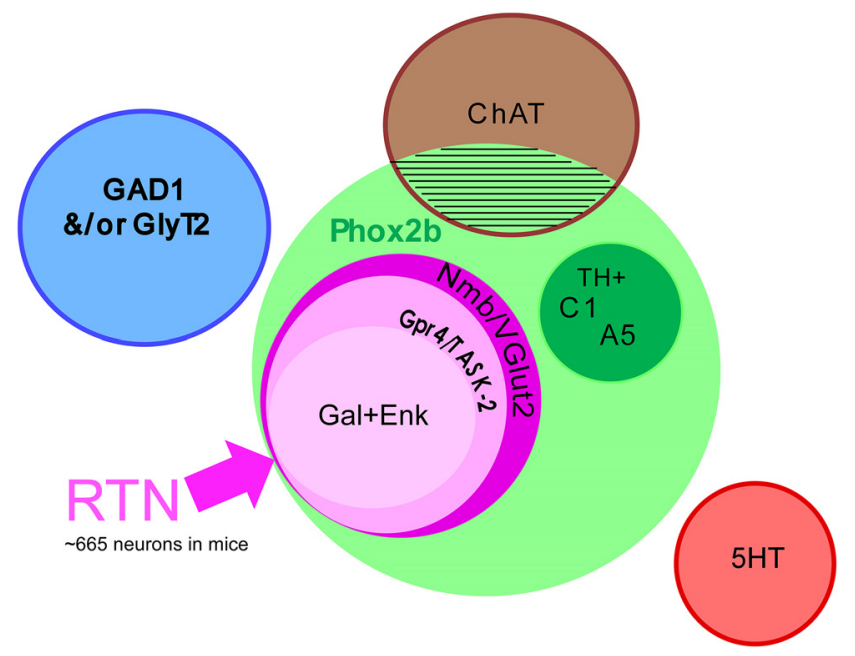

Figure 12. Venn diagram of RTN and other parafacial neurons in mice. The facial/parafacial region contains multiple types of Phox2b neurons (light green circle), which are either cholinergic, noradrenergic or glutamatergic. RTN in mice consists of $\sim 665$ Phox $2 b+$ glutamatergic (VGlut2+) neurons that express Nmb (dark pink circle). Most RTN neurons (80-90\%) contain proton sensors TASK-2 and Gpr4 (medium pink circle); these neurons are most probably central respiratory chemoreceptors. A subset of the latter $(>70 \%)$ express varying levels of $G$ al and/or Penk mRNA (light pink circle). Parafacial Nmb neurons do not express ChAT, Th, Tph(1 or 2), Gad1, or GlyT2. The size of the circles is not meant to represent relative number of neurons.

reactive for these peptides (Bochorishvili et al., 2012; Li et al., 2016). The other peptides have as yet to be identified in RTN terminals.

Every RTN neuron contains several pro-peptide transcripts. If peptide content is an indication of function, the code is probably combinatorial. The problem is further complicated as transcript levels, and presumably peptide expression, are not all or none but vary over a wide range.

\section{Stochastic gene expression or evidence for multiple functional subsets of RTN neurons?}

The transcript level for individual genes examined semiquantitatively by in situ hybridization and quantitatively by RNA-Seq varied considerably from cell to cell (e.g., by $1.5 \mathrm{log}$ units). Clearly, technical issues contribute to some variability for either of these methods, but the general concordance between them suggests that much of this reflects real differences in expression among individual neurons. For example, the generally inverse correlation between $N m b$ transcripts and mRNA for neuropeptides (Penk or Gal) and proton sensors (Gpr4 or Kcnk5) was detected by both methods, as was the paired and/or preferential expression of Gpr4 and Kcnk5 in individual RTN neurons.

The RTN is a numerically small group of neurons with a unique and well defined developmental genetic lineage (Ruffault et al., 2015). Nonetheless, gene expression in RTN neurons was surprisingly variable, suggesting that this relatively small and select population consists of multiple subtypes of neurons. This interpretation is supported by prior evidence of differential synaptic inputs and firing properties in several preparations (Guyenet et al., 2005; Onimaru et al., 2008; Thoby-Brisson et al., 2009). Subsets of RTN neurons with varying degrees of $\mathrm{CO}_{2}$ sensitivity and distinctive synaptic inputs may differentially regulate various breathing parameters (frequency, amplitude, etc.) and possibly other functions (e.g., arousal, cardiovascular control). Alternatively, the large variability in gene expression that we observed could mean that gene expression is simply stochastic, even among a small cluster of functionally homogeneous neurons.

\section{Conclusions}

All RTN neurons express Nmb in mice and rats (Fig. 12 for summary). $N m b$ also provides a quantitative trait that defines subsets of RTN neurons. Specifically, the cells expressing the highest levels of Nmb never express Gal and Penk, have lower levels of Gpr4 and Kcnk5, and do not express Fos after hypercapnia. The latter seems especially true for the Nmb-high RTN neurons $(\sim 20-$ $25 \%$ ) that are located at the outer reaches of this nucleus and may subserve a task distinct from the central respiratory chemoreceptor role of the majority of RTN neurons. Finally, based on Fos expression after hypercapnia at least $75 \%$ of RTN neurons qualify as potential central chemoreceptors, closely corresponding to the fraction of neurons expressing either Gpr4 or Kcnk5 (80-90\%). Since all these neurons express $N m b$, this transcript is a marker that, by itself, identifies RTN chemoreceptors with at least $75 \%$ fidelity.

\section{References}

Abercrombie M (1946) Estimation of nuclear population from microtome sections. Anat Rec 94:239-247. CrossRef Medline

Barna BF, Takakura AC, Mulkey DK, Moreira TS (2016) Purinergic receptor blockade in the retrotrapezoid nucleus attenuates the respiratory chemoreflexes in awake rats. Acta Physiol (Oxf) 217:80-93. CrossRef Medline

Basting TM, Burke PG, Kanbar R, Viar KE, Stornetta DS, Stornetta RL, Guyenet PG (2015) Hypoxia silences retrotrapezoid nucleus respiratory chemoreceptors via alkalosis. J Neurosci 35:527-543. CrossRef Medline

Becker HF, Polo O, McNamara SG, Berthon-Jones M, Sullivan CE (1996) Effect of different levels of hyperoxia on breathing in healthy subjects. J Appl Physiol 81:1683-1690. Medline

Bochorishvili G, Stornetta RL, Coates MB, Guyenet PG (2012) PreBötzinger complex receives glutamatergic innervation from galaninergic and other retrotrapezoid nucleus neurons. J Comp Neurol 520:10471061. CrossRef Medline

Burke PG, Kanbar R, Basting TM, Hodges WM, Viar KE, Stornetta RL, Guyenet PG (2015) State-dependent control of breathing by the retrotrapezoid nucleus. J Physiol 593:2909-2926. CrossRef Medline

Connelly CA, Ellenberger HH, Feldman JL (1990) Respiratory activity in retrotrapezoid nucleus in cat. Am J Physiol 258:L33-L44. Medline

Dubreuil V, Ramanantsoa N, Trochet D, Vaubourg V, Amiel J, Gallego J, Brunet JF, Goridis C (2008) A human mutation in Phox2b causes lack of $\mathrm{CO}_{2}$ chemosensitivity, fatal central apnoea and specific loss of parafacial neurons. Proc Natl Acad Sci U S A 105:1067-1072. CrossRef Medline

Ellenberger HH, Feldman JL (1990) Brainstem connections of the rostral ventral respiratory group of the rat. Brain Res 513:35-42. CrossRef Medline

Feldman JL, Mitchell GS, Nattie EE (2003) Breathing: rhythmicity, plasticity, chemosensitivity. Annu Rev Neurosci 26:239-266. CrossRef Medline

Gestreau C, Heitzmann D, Thomas J, Dubreuil V, Bandulik S, Reichold M, Bendahhou S, Pierson P, Sterner C, Peyronnet-Roux J, Benfriha C, Tegtmeier I, Ehnes H, Georgieff M, Lesage F, Brunet JF, Goridis C, Warth R, Barhanin J (2010) Task2 potassium channels set central respiratory $\mathrm{CO}_{2}$ and $\mathrm{O}_{2}$ sensitivity. Proc Natl Acad Sci U S A 107:2325-2330. CrossRef Medline

Goridis C, Dubreuil V, Thoby-Brisson M, Fortin G, Brunet JF (2010) Phox $2 b$, congenital central hypoventilation syndrome and the control of respiration. Semin Cell Dev Biol 21:814-822. CrossRef Medline

Gourine AV, Llaudet E, Dale N, Spyer KM (2005) ATP is a mediator of chemosensory transduction in the central nervous system. Nature 436: 108-111. CrossRef Medline

Gourine AV, Kasymov V, Marina N, Tang F, Figueiredo MF, Lane S, Teschemacher AG, Spyer KM, Deisseroth K, Kasparov S (2010) Astrocytes control breathing through pH-dependent release of ATP. Science 329: 571-575. CrossRef Medline

Guyenet PG, Bayliss DA (2015) Neural control of breathing and $\mathrm{CO}_{2}$ homeostasis. Neuron 87:946-961. CrossRef Medline

Guyenet PG, Mulkey DK, Stornetta RL, Bayliss DA (2005) Regulation of ventral surface chemoreceptors by the central respiratory pattern generator. J Neurosci 25:8938-8947. CrossRef Medline

Guyenet PG, Bayliss DA, Stornetta RL, Ludwig MG, Kumar NN, Shi Y, Burke 
PG, Kanbar R, Basting TM, Holloway BB, Wenker IC (2016) Proton detection and breathing regulation by the retrotrapezoid nucleus. J Physiol 594:1529-1551. CrossRef Medline

Hayes JA, Kottick A, Picardo MCD, Halleran AD, Smith RD, Smith GD, Saha MS, Del Negro CA (2017) Transcriptome of neonatal preBötzinger complex neurones in Dbx1 reporter mice. Sci Rep 7:8669. CrossRef Medline

Holloway BB, Viar KE, Stornetta RL, Guyenet PG (2015) The retrotrapezoid nucleus stimulates breathing by releasing glutamate in adult conscious mice. Eur J Neurosci 42:2271-2282. CrossRef Medline

Huckstepp RT, Cardoza KP, Henderson LE, Feldman JL (2015) Role of parafacial nuclei in control of breathing in adult rats. J Neurosci 35:10521067. CrossRef Medline

Kumar NN, Velic A, Soliz J, Shi Y, Li K, Wang S, Weaver JL, Sen J, Abbott SB, Lazarenko RM, Ludwig MG, Perez-Reyes E, Mohebbi N, Bettoni C, Gassmann M, Suply T, Seuwen K, Guyenet PG, Wagner CA, Bayliss DA (2015) Regulation of breathing by $\mathrm{CO}_{2}$ requires the proton-activated receptor GPR4 in retrotrapezoid nucleus neurons. Science 348:12551260. CrossRef Medline

Lazarenko RM, Milner TA, Depuy SD, Stornetta RL, West GH, Kievits JA, Bayliss DA, Guyenet PG (2009) Acid sensitivity and ultrastructure of the retrotrapezoid nucleus in Phox2b-EGFP transgenic mice. J Comp Neurol 517:69-86. CrossRef Medline

Lazarenko RM, Stornetta RL, Bayliss DA, Guyenet PG (2011) Orexin A activates retrotrapezoid neurons in mice. Respir Physiol Neurobiol 175: 283-287. CrossRef Medline

Lein ES, Hawrylycz MJ, Ao N, Ayres M, Bensinger A, Bernard A, Boe AF, Boguski MS, Brockway KS, Byrnes EJ, Chen L, Chen L, Chen TM, Chin MC, Chong J, Crook BE, Czaplinska A, Dang CN, Datta S, Dee NR, et al. (2007) Genome-wide atlas of gene expression in the adult mouse brain. Nature 445:168-176. CrossRef Medline

Li P, Janczewski WA, Yackle K, Kam K, Pagliardini S, Krasnow MA, Feldman JL (2016) The peptidergic control circuit for sighing. Nature 530:293297. CrossRef Medline

Liu JL, Kulakofsky J, Zucker IH (2002) Exercise training enhances baroreflex control of heart rate by a vagal mechanism in rabbits with heart failure. J Appl Physiol 92:2403-2408. CrossRef Medline

Loeschcke HH (1982) Central chemosensitivity and the reaction theory. J Physiol 332:1-24. CrossRef Medline

Ludwig MG, Vanek M, Guerini D, Gasser JA, Jones CE, Junker U, Hofstetter H, Wolf RM, Seuwen K (2003) Proton-sensing G-protein-coupled receptors. Nature 425:93-98. CrossRef Medline

Marina N, Abdala AP, Trapp S, Li A, Nattie EE, Hewinson J, Smith JC, Paton JF, Gourine AV (2010) Essential role of Phox2b-expressing ventrolateral brainstem neurons in the chemosensory control of inspiration and expiration. J Neurosci 30:12466-12473. CrossRef Medline

Mulkey DK, Stornetta RL, Weston MC, Simmons JR, Parker A, Bayliss DA, Guyenet PG (2004) Respiratory control by ventral surface chemoreceptor neurons in rats. Nat Neurosci 7:1360-1369. CrossRef Medline

Mulkey DK, Rosin DL, West G, Takakura AC, Moreira TS, Bayliss DA, Guyenet PG (2007) Serotonergic neurons activate chemosensitive retrotrapezoid nucleus neurons by a pH-independent mechanism. J Neurosci 27: 14128-14138. CrossRef Medline

Onimaru H, Homma I (2003) A novel functional neuron group for respiratory rhythm generation in the ventral medulla. J Neurosci 23:1478-1486. Medline

Onimaru H, Ikeda K, Kawakami K (2008) $\mathrm{CO}_{2}$-sensitive preinspiratory neurons of the parafacial respiratory group express Phox $2 \mathrm{~b}$ in the neonatal rat. J Neurosci 28:12845-12850. CrossRef Medline
Onimaru H, Ikeda K, Mariho T, Kawakami K (2014) Cytoarchitecture and $\mathrm{CO}_{2}$ sensitivity of Phox 2b-positive parafacial neurons in the newborn rat medulla. Prog Brain Res 209:57-71. CrossRef Medline

Patro R, Duggal G, Love MI, Irizarry RA, Kingsford C (2017) Salmon provides fast and bias-aware quantification of transcript expression. Nat Methods 14:417-419. CrossRef Medline

Paxinos G, Franklin KBJ (2013) The mouse brain in stereotaxic coordinates, Ed 4. New York: Academic.

Paxinos G, Watson C (2005) The rat brain in stereotaxic coordinates, Ed 5. San Diego: Elsevier/Academic.

Ramanantsoa N, Hirsch MR, Thoby-Brisson M, Dubreuil V, Bouvier J, Ruffault PL, Matrot B, Fortin G, Brunet JF, Gallego J, Goridis C (2011) Breathing without $\mathrm{CO}_{2}$ chemosensitivity in conditional Phox $2 b$ mutants. J Neurosci 31:12880-12888. CrossRef Medline

Reyes R, Duprat F, Lesage F, Fink M, Salinas M, Farman N, Lazdunski M (1998) Cloning and expression of a novel $\mathrm{pH}$-sensitive two pore domain K+ channel from human kidney. J Biol Chem 273:30863-30869. CrossRef Medline

Rudzinski E, Kapur RP (2010) PHOX2B immunolocalization of the candidate human retrotrapezoid nucleus. Pediatr Dev Pathol 13:291-299. CrossRef Medline

Ruffault PL, D'Autreaux F, Hayes JA, Nomaksteinsky M, Autran S, Fujiyama T, Hoshino M, Hagglund M, Kiehn O, Brunet JF, Fortin G, Goridis C (2015) The retrotrapezoid nucleus neurons expressing Atohl and Phox $2 \mathrm{~b}$ are essential for the respiratory response to $\mathrm{CO}_{2}$. eLife 4:e07051. CrossRef Medline

Shi Y, Abe C, Holloway BB, Shu S, Kumar NN, Weaver JL, Sen J, Perez-Reyes E, Stornetta RL, Guyenet PG, Bayliss DA (2016) Nalcn is a "leak" sodium channel that regulates excitability of brainstem chemosensory neurons and breathing. J Neurosci 36:8174-8187. CrossRef Medline

Smith JC, Morrison DE, Ellenberger HH, Otto MR, Feldman JL (1989) Brainstem projections to the major respiratory neuron populations in the medulla of the cat. J Comp Neurol 281:69-96. CrossRef Medline

Soneson C, Love MI, Robinson MD (2015) Differential analyses for RNAseq: transcript-level estimates improve gene-level inferences. F1000Res 4:1521. CrossRef Medline

Stornetta RL, McQuiston TJ, Guyenet PG (2004) GABAergic and glycinergic presympathetic neurons of rat medulla oblongata identified by retrograde transport of pseudorabies virus and in situ hybridization. J Comp Neurol 479:257-270. CrossRef Medline

Stornetta RL, Moreira TS, Takakura AC, Kang BJ, Chang DA, West GH, Brunet JF, Mulkey DK, Bayliss DA, Guyenet PG (2006) Expression of Phox $2 \mathrm{~b}$ by brainstem neurons involved in chemosensory integration in the adult rat. J Neurosci 26:10305-10314. CrossRef Medline

Stornetta RL, Spirovski D, Moreira TS, Takakura AC, West GH, Gwilt JM, Pilowsky PM, Guyenet PG (2009) Galanin is a selective marker of the retrotrapezoid nucleus in rats. J Comp Neurol 512:373-383. CrossRef Medline

Thoby-Brisson M, Karlén M, Wu N, Charnay P, Champagnat J, Fortin G (2009) Genetic identification of an embryonic parafacial oscillator coupling to the preBötzinger complex. Nat Neurosci 12:1028-1035. CrossRef Medline

Wang S, Shi Y, Shu S, Guyenet PG, Bayliss DA (2013a) Phox2b-expressing retrotrapezoid neurons are intrinsically responsive to acidification and $\mathrm{CO}_{2}$. J Neurosci 33:7756-7761. CrossRef Medline

Wang S, Benamer N, Zanella S, Kumar NN, Shi Y, Bévengut M, Penton D, Guyenet PG, Lesage F, Gestreau C, Barhanin J, Bayliss DA (2013b) TASK-2 channels contribute to $\mathrm{pH}$ sensitivity of retrotrapezoid nucleus chemoreceptor neurons. J Neurosci 33:16033-16044. CrossRef Medline 